\title{
The Essential Role of Primate Orbitofrontal Cortex in Conflict-Induced Executive Control Adjustment
}

\author{
Farshad A. Mansouri, ${ }^{1,3}$ Mark J. Buckley, ${ }^{2}$ and Keiji Tanaka ${ }^{1}$ \\ ${ }^{1}$ Cognitive Brain Mapping Laboratory, RIKEN Brain Science Institute, Wako, Saitama 351-0198, Japan, ${ }^{2}$ Department of Experimental Psychology, Oxford \\ University, Oxford OX1 3UD, United Kingdom, and '3Department of Physiology, Monash University, Clayton, Victoria 3800, Australia
}

Conflict in information processing evokes trial-by-trial behavioral modulations. Influential models suggest that adaptive tuning of executive control, mediated by mid-dorsal lateral prefrontal cortex (mdlPFC) and anterior cingulate cortex (ACC), underlies these modulations. However, mdlPFC and ACC are parts of distributed brain networks including orbitofrontal cortex (OFC), posterior cingulate cortex (PCC), and superior-dorsal lateral prefrontal cortex (sdlPFC). Contributions of these latter areas in adaptive tuning of executive control are unknown. We trained monkeys to perform a matching task in which they had to resolve the conflict between two behavior-guiding rules. Here, we report that bilateral lesions in OFC, but not in PCC or sdlPFC, impaired selection between these competing rules. In addition, the behavioral adaptation that is normally induced by experiencing conflict disappeared in OFC-lesioned, but remained normal in PCC-lesioned or sdlPFC-lesioned monkeys. Exploring underlying neuronal processes, we found that the activity of neurons in OFC represented the conflict between behavioral options independent from the other aspects of the task. Responses of OFC neurons to rewards also conveyed information of the conflict level that the monkey had experienced along the course to obtain the reward. Our findings indicate dissociable functions for five closely interconnected cortical areas suggesting that OFC and mdlPFC, but not PCC or sdlPFC or ACC, play indispensable roles in conflict-dependent executive control of on-going behavior. Both mdlPFC and OFC support detection of conflict and its integration with the task goal, but in contrast to mdlPFC, OFC does not retain the necessary information for conflict-induced modulation of future decisions.

Key words: conflict; executive control; lesion study; orbitofrontal cortex

\section{Introduction}

The presence of conflict between behavioral choices adversely affects performance in terms of speed and accuracy (conflict cost; Botvinick et al., 2001; Carter and van Veen, 2007; Egner, 2007; Mansouri et al., 2009). The behavioral effect of conflict is not limited to the current trial, but the experience of a conflict also influences the performance in the following trial when the subject makes a decision between the competing choices again; this effect appears as an improved performance in resolving the conflict (conflict adaptation effect; Botvinick et al., 2001; Carter and van Veen, 2007). Conflict-induced behavioral modulations have been considered as consequences of trial-by-trial contextdependent tunings of executive control (Botvinick et al., 2001; Carter and van Veen, 2007; Egner, 2007; Mansouri et al., 2009) that aim to facilitate conflict resolution. Patients with prefrontal

\footnotetext{
Received April 23, 2014; revised June 22, 2014; accepted June 26, 2014

Author contributions: F.A.M., M.J.B., and K.T. designed research; F.A.M., M.J.B., and K.T. performed research; F.A.M., M.J.B., and K.T. analyzed data; F.A.M., M.J.B., and K.T. wrote the paper.

This work was supported by the Grant-in-Aid for Scientific Research A19200027 and the Japan Society for the Promotion of Science through the Funding Program for World-Leading Innovative R\&D on Science and Technology (FIRST Program). We thank fMRI Support Unit for taking the MRIs and T. Hashikawa for histology.

The authors declare no competing financial interests.

This article is freely available online through the J Neurosci Author Open Choice option.

Correspondence should be addressed to Dr Farshad A. Mansouri, Cognitive Brain Mapping Laboratory, RIKEN Brain Science Institute, 2-1 Hirosawa, Wako, Saitama 351-0198, Japan. E-mail: farshad.mansouri@monash.edu. DOI:10.1523/JNEUROSCI.1637-14.2014

Copyright $\odot 2014$ the authors $\quad 0270-6474 / 14 / 3411016-16 \$ 15.00 / 0$
}

damage and various neurological disorders show altered patterns of conflict-induced behavioral adjustment (Bench et al., 1993; Goldstein et al., 2001; Mitchell, 2005; Carter and van Veen, 2007). Therefore, studying neural mechanisms involved in the conflictdependent executive control is necessary to gain insight to the neural basis of executive control functions and the neuropathology of brain damage and disorder.

Whereas the contribution of anterior cingulate cortex (ACC) and mid-dorsal lateral prefrontal cortex (mdlPFC) to executivecontrol adjustment have been studied extensively, the contributions of orbitofrontal cortex (OFC), posterior cingulate cortex (PCC), and superior-dorsal lateral prefrontal cortex (sdlPFC) have not been given focus in previous lesion-behavioral and electrophysiology studies in primates. All three regions have extensive neuroanatomical connections with mdlPFC and ACC (Baleydier and Mauguiere, 1980; Vogt et al., 1992; Petrides, 2005; Pearson et al., 2011), and imaging studies have shown conflictrelated activation changes in these areas (Bench et al., 1993; Cavada et al., 2000; Botvinick et al., 2001; Goldstein et al., 2001; Mitchell, 2005; Carter and van Veen, 2007; Egner, 2007; Mansouri et al., 2009). It is generally assumed that OFC plays a crucial role in motivational aspects of goal-directed behavior by processing reward information (Lee et al., 2007; Wallis, 2007; Watanabe and Sakagami, 2007; Padoa-Schioppa and Assad, 2008; Simmons and Richmond, 2008; Schoenbaum et al., 2009; Peters and Büchel, 2010; Rushworth et al., 2011). It has recently been sug- 
High-conflict $(\mathrm{H})$ condition

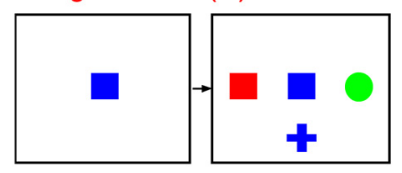

Low-conflict (L) condition

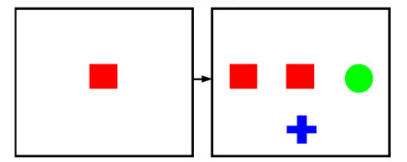

Sample period Choice period
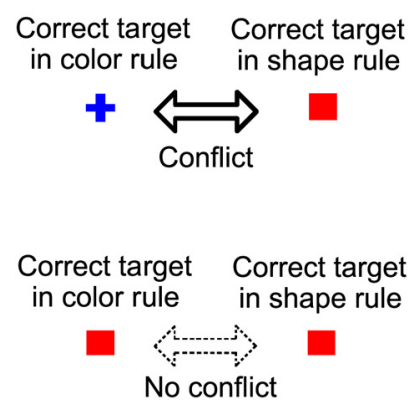

Figure 1. WCST analog used in lesion study. Trials with low- and high-conflict conditions were intermingled. Trials started by sample onset on a touchscreen and after the monkey touched the sample and released its hand, three test items appeared surrounding the sample and animals had to match the central sample with one of three surrounding test items based on whether a color-matching or a shape-matching rule was currently reinforced.

gested that PCC is involved in the saliency and change detection and the ensuing adjustment in behavior (Baleydier and Mauguiere, 1980; McCoy and Plat, 2005; Pearson et al., 2011). Previous studies have suggested a functional distinction between sdlPFC and the cortex surrounding principal sulcus (PS) in working memory processes (Petrides, 2005; Buckley et al., 2009). However, the function of OFC, PCC, and sdlPFC in conflict processing remains unclear.

The Wisconsin Card Sorting Test (WCST; Mansouri et al., 2007,2009 ) provides a changing environment in which a conflict exists between behavioral rules and a successful performance depends on the proper resolution of conflict and therefore is a suitable test to examine the contribution of OFC, PCC, and sdlPFC to conflict processing and conflict-related executive control adjustment. Using WCST, we found functional dissociation between these areas in conflict processing.

\section{Materials and Methods}

Subjects. Eleven male monkeys (Macaca mulatta and M. fuscata) were used: three of them were trained, operated, and tested in Oxford, UK (2 were assigned to the OFC lesion group and 1 to the sdlPFC lesion group), and eight in the RIKEN Brain Science Institute, Wako, Japan. All animal training, surgery, and experimental procedures were the same in both laboratories. The lesions were introduced after a minimum of 12 months of preoperative training with the WCST analog. Neuronal activity recordings were conducted in the cortex between the medial and lateral orbital sulci (see Fig. 7C, light blue shaded area) from two monkeys after each monkey had been trained for $\sim 18$ months. Those experiments conducted in the UK were licensed in compliance with the UK Animals Scientific Procedures Act 1986, and those in Japan were done in accordance with the guidelines of the Japanese Physiological Society, and approved by RIKEN's Animal Experiment Committee.

\section{Lesion study}

Nine of the monkeys were used for lesion study. Three of them received bilateral lesions in OFC, three others in PCC and the remaining three in sdlPFC.

Apparatus and stimuli. The tasks (Figs. 1, Fig. 7A) were provided in automated test apparatuses as described in our previous study (Mansouri et al., 2007; Buckley et al., 2009). The subject sat, unrestrained, in a wheeled transport cage fixed in position in front of a touch-sensitive screen on which the stimuli were displayed. A computer, with a millisecond accuracy timer-card to record response times, controlled the experiment and conducted data acquisition. The versions of the WCST used in this lesion study used 36 different stimuli comprising of six colors (red, yellow, green, cyan, blue, and magenta) and six shapes (square, triangle, circle, hexagon, cross, and ellipse). The sample in each trial was selected at random (without replacement until the entire set had been used) from the 36 stimuli. In each trial the test items were also selected from the same set of 36 stimuli, and at random (with the restrictions imposed by the necessity to generate either a low- or high-conflict trial). The locations of the three test items (i.e., to the left/right/bottom of the sample) were also chosen at random. The size of the stimuli was $5-6 \mathrm{~cm}$ on the screen. The center-to-center distance between the test items and sample was $15 \mathrm{~cm}$ on the screen.

Behavioral task. The monkeys had to match the sample to one of three test items either by color or by shape and touch the correct item within $5000 \mathrm{~ms}$ to receive a reward. A reward or a distinct visual error signal (white annulus) was given as feedback after monkeys' correct or erroneous matching, respectively. The relevant rule and its frequent changes were not cued. Even the reward and error signal by themselves did not indicate the relevant rule directly and therefore the subjects faced a conflict/competition between the potential matching rules. The monkeys were only able to identify it by applying a rule and then interpreting the reward or error feedback in the context of the applied rule. The relevant rule for matching (matching by shape or matching by color) was consistent within a block of trials, and it changed whenever a criterion of $85 \%$ correct performance was achieved in 20 consecutive trials. In individual trials the monkeys performed the task under one of two different levels of conflict, namely low-conflict (L) and high-conflict (H; Fig. 1). In the high-conflict condition, the sample matched one of the test items in color and another test item in shape but it did not match the remaining test item in either color or shape. Therefore, the monkeys had to resolve the competition between two potential matching rules (i.e., matching by color and matching by shape) to select the target. In the low-conflict condition, the sample matched one of the test items in both color and shape but it did not match the other two test items in either color or shape, thus there was no conflict between the two matching rules. The low- and high-conflict trials were randomly intermingled and presented in equal proportion. (Fig. 1).

Repetition of sample as a confounding issue. The probability that a correct response to a sample was followed by the presentation of the same sample in the next trial is a matter of concern in studies of conflictinduced behavioral adjustment (Mayr et al., 2003). In the task paradigms used in our lesion and recording studies, the possibility of sample repetition was very low because samples were selected without replacement: all stimuli in the set (36 samples) had to be exhausted before the next set starts. Only at the start of a new set, there was a possibility (0.03) for the repetition of the same sample as that shown in the previous trial. Moreover, because the correct test item was randomly selected from five stimuli, the probability of a repetition of identical pair of sample and correct test item was even smaller.

Surgery. The monkey was moved into the operating theater, intubated, placed on isoflurane anesthesia (1-2.75\%, to effect, in 100\% oxygen), and then mechanically ventilated. The skin and underlying galea were opened in layers. The temporal muscles were retracted to expose the skull surface and a bone flap was turned to allow access to the desired lesion site. The dura was cut and reflected to expose the cortex and the lesion was made in the intended site by aspiration. A small-gauge metal aspirator equipped with an electro-coagulator was used to aspirate the cortex. The aspiration was done using an operating microscope and white matter under the cortex, which is easily distinguishable from gray matter, was spared as much as possible to the extent that white matter damage was minimal. The operated monkeys rested for $\sim 14 \mathrm{~d}$ after surgery before beginning postoperative training.

Among various lesion techniques, the neuroexcitotoxic method has an advantage in that it spares fibers passing through or near the target area. However, a complete lesion in cortical areas requires a large amount of toxic compound administration at multiple locations and in many published studies the cell body damage is often very far from complete and rarely bilaterally symmetrical; furthermore in relatively inaccessible areas like OFC the cortex has to be repeatedly manipulated to gain repeated access for the numerous injections required and this causes bruising and/or odemea outside of the intended lesion area. For example, in the recent study by Rudebeck et al. (2013), between 44 and 97\% of cells in each hemisphere were affected indicating that the extent of lesion was 
very variable and could be significantly incomplete in a particular hemisphere, and at some levels apparently outside of the intended extent of the lesion. Increasing the amount of injected toxin has the disadvantage of possible spread to nearby cortical and/or subcortical areas. In contrast, lesions made by careful aspiration technique are visually guided through an operating microscope and can be used to remove the entire cortex in the intended area, and in some areas in the right hands brings the highest precision in limiting the extent of cortical lesion; it may be impossible to preclude any white matter damage but the extent of the damage when done carefully is minimal. In our study, the white matter damage was minimized by first cauterizing around the periphery of the lesion so that the cortex within this boundary was devoid of blood supply. This enabled a very conservative approach: we stopped the aspiration either immediately after the white matter became visible (which is extremely clear) or just before this. Any layers of cortex left intact in the area of the lesion would not survive in the absence of blood supply.

Intended extent of lesions. The intended extent of the OFC lesion (Fig. 2) included at its lateral extent, the cortex in the medial bank of the lateral orbital sulcus; the lesion included the entire cortex between the medial and lateral orbital sulci, and also extended medially until the lateral bank of the rostral sulcus. The anterior extent of the lesion was an imaginary line drawn between the anterior tips of the lateral and medial orbital sulcii, and the posterior extent was an imaginary line drawn just anterior to the posterior tips of these two sulcii. The intended lesion therefore included cortical areas 11,13, and 14 of the orbital surface and did not extend posteriorly into the agranular insula.

The lesion extent in the three PCC-lesioned monkeys included cortex in the posterior cingulate gyrus and lower bank of posterior cingulate sulcus extending as far posteriorly as to include area 31 (retrosplenial cortex excluded; Vogt et al., 1992; Fig. 3).

The lesion extent in sdlPFC group included the cortex on the dorsolateral aspect of the prefrontal cortex starting $1 \mathrm{~mm}$ dorsal to the principal sulcus and extending dorsally up to the midline (i.e., lateral area 9 and the dorsal portions of areas 46 and 9/46) but excluding ventrally situated cortex that lay within the principal sulcus area; the lesion excluded posteriorly located premotor areas $8 \mathrm{~A}, 8 \mathrm{Bd}$, and $8 \mathrm{Bv}$, nor did it extend anteriorly into area 10 (Fig. 4).

Histology. At the conclusion of the experiments, animals with OFC or sdlPFC lesion were deeply anesthetized and then perfused through the heart with saline followed by formol-saline solution. Their brains were blocked in the coronal stereotaxic plane, removed from the skull, and allowed to sink in sucrose-formalin solution, and subsequently cut in 50 $\mu \mathrm{m}$ sections on a freezing microtome. Every fifth or tenth section was retained and stained with cresyl violet.

Data analyses. Data were collected from six consecutive preoperative and postoperative daily sessions. All the monkeys completed at least eight blocks of trials in each of the six sessions preoperatively, with one exception. One monkey in the OFC group could not complete eight blocks in one of the preoperative sessions, and then an additional session was introduced. We used session means when we evaluated the number of rule-shifts and percentage of correct responses by ANOVA. The analyses of response time focused on daily sessions with at least eight blocks (a block of trials starts from a rule change and ends with another rule change). The last block was included in the analyses if the monkeys had completed at least 20 trials in that block. The data for analyses of number of rule-shifts and percentage of correct responses were collected from all the sessions.

We measured the time from the onset of the test items to the monkey's first touch on the screen as the response time (RT) and took its reciprocal (1/RT) to obtain the speed of target selection (STS) in individual trials. We then averaged the STS separately for each conflict condition (either low-conflict/high-conflict or LH/HH) and response direction (left/right/ bottom) across daily sessions of each monkey. $\mathrm{HH}$ is a high-conflict trial following a high-conflict trial and LH is a high-conflict trial following a low-conflict trial. Thus, we obtained a pair of STS values (either lowconflict/high-conflict or $\mathrm{LH} / \mathrm{HH}$ ) for each response direction of each monkey. Then, the values were averaged across directions within each conflict condition. To compare the effects of conflict between the preoperative and postoperative performances, differences between the two

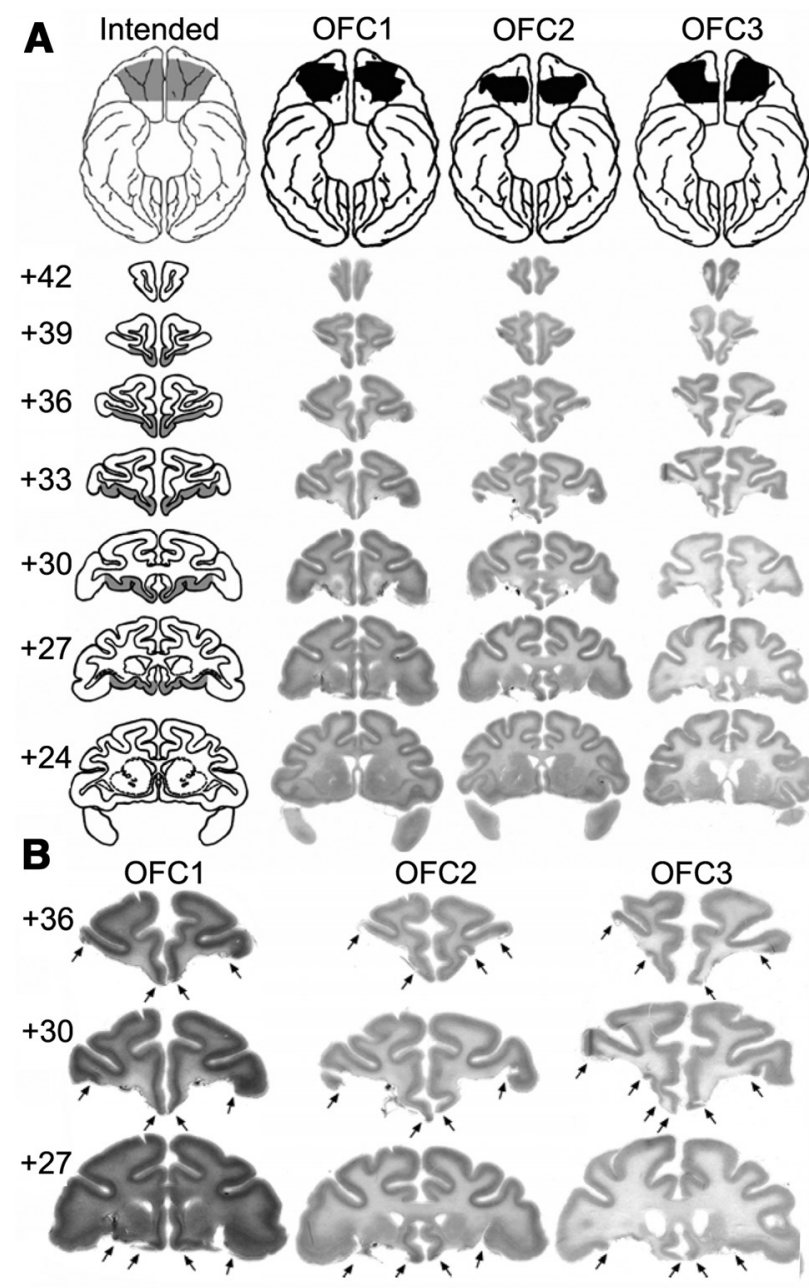

Figure 2. Extent of bilateral OFC lesion. $\boldsymbol{A}$, This figure depicts photomicrographs of stained coronal sections through the area of the intended lesion in the three animals with OFC lesions (OFC1 to OFC3) alongside drawings of the intended extent of the lesions on drawings of representative coronal sections (left column). The top row shows reconstructions of the area of cortex lesioned on drawings of a representative ventral surface. Numerals indicate the distance in millimeters from the interaural plane. None of the OFC lesioned animals sustained any bilateral damage outside the area of the intended region; two animals, OFC2 and OFC3, sustained extremely slight unilateral damage beyond the intended lateral boundary of the lesion; and in all three animals the lesions did not extent as far medially as intended. $\boldsymbol{B}$, Photomicrographs of stained coronal sections through the area of the intended lesion in the three animals with OFC lesions ( $0 F C 1$ to $0 F(3)$. Numerals indicate the distance in millimeters from the interaural plane. The black arrows point to the most lateral and medial extent of the lesion in each section indicating that the lesion extent was limited to the intended orbitofrontal cortex. Extensive white matter can be seen to remain intact in the region just dorsal to and between the tips of these arrows.

conflict conditions (low-conflict, high-conflict, or HH-LH) were calculated in each monkey and then a paired $t$ test was applied to the preoperative and postoperative differences. In Figure 2, to ease comparing the changes in STS between monkeys and groups, the values were normalized in each monkey by dividing the value in each condition by the mean of the paired conditions $[\mathrm{H} /$ mean $(\mathrm{L}, \mathrm{H}) ; \mathrm{L} /$ mean $(\mathrm{L}, \mathrm{H}) ; \mathrm{LH} /$ mean $(\mathrm{LH}$, $\mathrm{HH}) ; \mathrm{HH} /$ mean $(\mathrm{LH}, \mathrm{HH})]$ in each monkey.

Overall, the response speed of monkeys significantly decreased after OFC lesion so that in some trials the response time was extraordinarily long (Buckley et al., 2009). To remove these outliers, in every preoperative and also postoperative session the trials in which the response time was outside a range (mean $\pm 2 \times \mathrm{SD}$ of the response times for each response direction in that daily session) were excluded from the analyses. 
A Intact
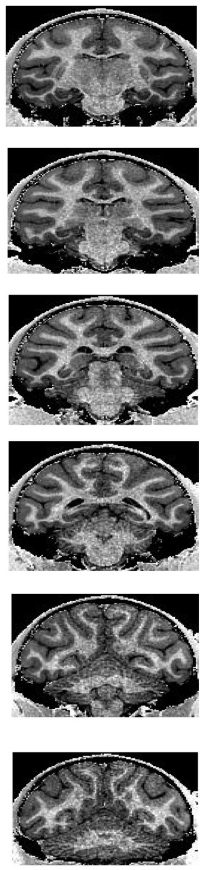

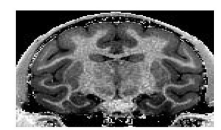

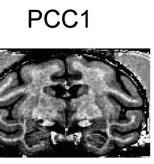
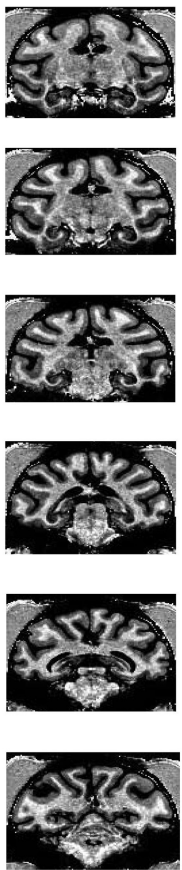
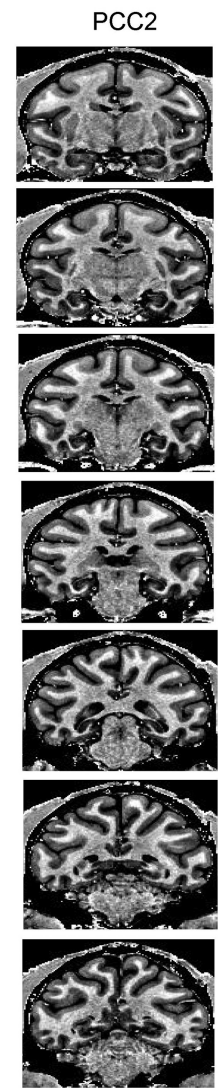

PCC2

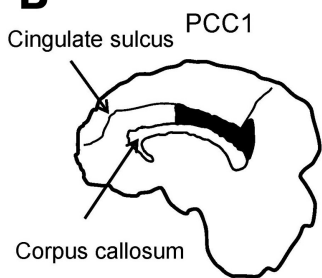

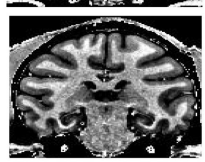

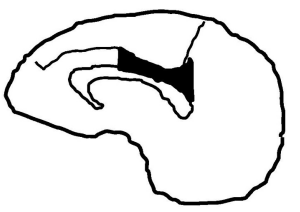

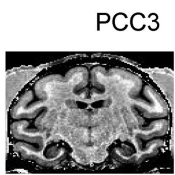
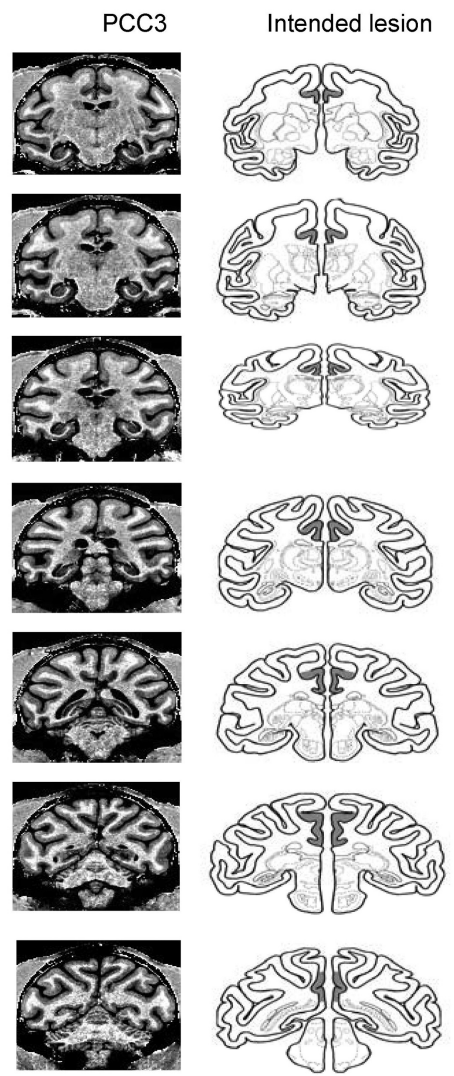

PCC3

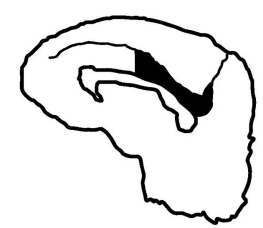

Figure 3. Extent of PCC lesions confirmed in magnetic resonance imaging (MRI). $\boldsymbol{A}$, MRI scans were taken after the end of postoperative data collection to verify the lesion extent. The left-most column is for an intact monkey (Intact) and three middle columns are for the three $\mathrm{PCC}$-lesioned monkeys $(\mathrm{PCC} 1-\mathrm{PCC} 3)$ and the right-most column shows the intended lesion extent on drawings of a representative brain. Coronal sections are taken from seven anterior-posterior levels covering the posterior cingulate cortex in each monkey. The sections in PCC-lesioned monkeys were selected so that their gyri and sulci shapes match those of the intact monkey as much as possible. The gray matter tissues are missing bilaterally in the ventral bank of cingulate sulcus and on the surface of posterior cingulate gyrus in each PCC-lesioned animal. The lesions of posterior cingulate cortex were as intended with no damage outside the target area. $\boldsymbol{B}$, Extent of $\mathrm{PCC}$ lesion in the medial view of the brain. The shapes of the brain, corpus callosum, and cingulate sulcus, together with the lesion extent, were reconstructed from structural MRIs in each monkey. The black areas indicate the lesion extent.

\section{Recording study}

Two macaque monkeys (M. fuscata, M1 and M2) were trained, operated, and used for recordings in RIKEN Brain Science Institute. The details of training and recording technique were previously reported (Mansouri et al., 2006, 2007).

Behavioral task. The structure, criteria, and parameters of the WCST analog used for the electrophysiology study were similar to those used for the lesion study, with some modifications to facilitate single-cell recordings and interpretation of neuronal activities (see Figs. $7 A, B, 8$ ). In each trial, a start cue appeared when an intertrial interval was over. The bar pressing changed the start cue to a fixation point. If the monkey kept pushing the bar and maintained its gaze on the fixation point for $700 \mathrm{~ms}$, a sample stimulus replaced the fixation point. If the monkey maintained eye fixation and bar press for another $630 \mathrm{~ms}$, three test items appeared (to the left, right, and below the sample). Reward or error-signal was presented $700 \mathrm{~ms}$ after the monkey touched the screen. For the recording

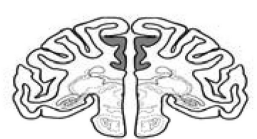

study we used CORTEX software (NIMH CORTEX, RRID:nif-0000-04365) to control the experiment and data acquisition.

We used 36 stimuli identical to those used in the lesion studies. A sample was randomly selected from the 36 stimuli without replacement (all 36 stimuli were used before starting another cycle). Twelve samples were consistently used in low-conflict conditions, and other 24 samples were consistently used in high-conflict conditions. We used four fixed arrangements of test items to make low- and high-conflict conditions (see Fig. 8). The monkeys were extensively trained with these fixed arrangements of samples and test items.

Free-reward trials. Trials in which reward was delivered without performing the matching task (free-reward trials) were randomly presented between the usual WCST trials (in $4 / 40$ of trials). The structure of free-reward trials was similar to that in the usual trials in their early parts (see Fig. 7B). After the start-cue appearance, the monkey had to push the bar and fixate the eyes during the fixation period. If the monkey kept pushing the bar and fixating the eyes to the end of fixation period, instead of sample appearance, a reward was delivered and the trial ended.

After the monkeys had learned the task, magnetic resonance images of the brain were taken, and the head holder and recording chamber were implanted in an aseptic surgery. After a week of recovery, training was resumed but now with head fixation and gaze control. Eye position was monitored by an infrared system (http://staff.aist.go.jp/k.matsuda/eye/). The monkeys had to keep their gaze fixed on the fixation point during the fixation and sample presentation periods. We kept the fixation point at the center of the sample. The size of fixation window was $4^{\circ}\left( \pm 2^{\circ}\right.$ from the fixation point center), which was smaller than any sample $\left(5\right.$ to $\left.\sim 7^{\circ}\right)$. Fixation-break trials were not included in the calculation of shift criterion.

Single-cell recording. Recordings started after each monkey had been trained for $\sim 18$ months. The recording area covered the area between the medial and lateral orbital sulci, (see Fig. 7C, dark blue area). The electrodes were guided through a chamber installed over dorsolateral surface of the brain. Glass-coated electrodes penetrated through intact dura. The electrodes were advanced slowly toward OFC to decrease physical damage to the brain tissue. The recording area was determined in reference to the magnetic resonance images. The border and extent of the white and gray matters were determined by tracking the neuronal activity through the slowly advancing electrode (the maximum speed of electrode advancement in brain tissue was $9 \mu \mathrm{m} / \mathrm{s}$ ) to help verify the position of OFC. Plexon system (NeuroExplorer: Neurophysiological Data Analysis Package, RRID:nif-0000-10382) was used for amplification, filtering and monitoring of the neuronal activities. Signals from a single cell were isolated on-line and checked by off-line verification. We did not observe any regional difference in the characteristics of cells within the recorded area. Therefore, results were reported for all of the recorded cells.

Data analyses. The analyses were performed in those sessions in which the neuronal activity was well isolated in at least four consecutive blocks. Cells (183 and 61) were recorded from M1 and M2, respectively. Firing 
rates were analyzed in the fixation period (600 ms before sample onset), sample period (600 $\mathrm{ms}$ starting from $30 \mathrm{~ms}$ after sample onset), and decision period ( $600 \mathrm{~ms}$ following onset of test items), the pre-reward period ( $800 \mathrm{~ms}$ before reward delivery) and the postreward period $(800 \mathrm{~ms}$ starting from the reward delivery). There was no significant difference in the proportion of cells representing different cognitive processes between the cells recorded from monkeys M1 and M2 and therefore we reported the neuronal activity for the population of cells recorded from both monkeys.

To study the effect of current level of conflict on cellular activity, we focused our analyses on the neuronal activity in the sample and decision periods, because only after the appearance of the sample could the monkey know whether a trial would be of the low-conflict or highconflict condition. The activity was compared between low-conflict and high-conflict trials by a two-way ANOVA (conflict $\times$ rule). The mean firing rate during either the sample or decision period in each trial was a data point. Because STS differed between low-conflict and high-conflict trials, an analysis of cell activities with a time window around the response may have been contaminated by an artifact: activities locked to the test items onset or monkey's response might have shown a pseudo dependency on the trial type by truncating rising or falling activities locked to one event by the window locked to the other event. To exclude such effects, we first examined the correlation between cell activities and STSs, after subtracting the difference in mean values between $\mathrm{H}$ and $\mathrm{L}$ trials. If there was a significant correlation $(p<$

0.10 ), we calculated the slope of the linear regression line and subtracted STS-dependent components of cell activities from the original (before the mean difference subtraction) values of cell activities in individual lowconflict and high-conflict trials. This correction was conducted only for the decision period because in the sample period the monkeys' hand and eye position was fixed and the monkeys could initiate the response only after the onset of test items, which was the beginning of the decision period. In the selection of cells with significant activity modulation by a two-way ANOVA, when both the main effect of a factor and interaction of factors were considered, we adjusted the acceptance level from $\leq 0.05$ to $\leq 0.025$.

We analyzed the effect of the conflict level experienced in the previous trial in fixation, sample and decision periods. The neuronal activity during fixation period has unique interests, because the monkey had not been able to know the conflict level in the coming trial before the sample onset. The activity in sample and decision periods were analyzed separately, because we found that different groups of OFC cells showed significant activity modulation depending on the conflict level in the current trial. In other words, the cell that showed a significant activity modulation by conflict level in sample period might not show any significant activity modulation during decision period. Therefore, the statistical analyses results and characteristics of neuronal activity were reported separately for each period. In each group of cells showing a significant modulation in a particular period, there were cells with higher activity in low-conflict conditions and others with higher activity in high-conflict conditions. Therefore, when we show pupulation neuronal activity, we averaged activity for the preferred and nonpreferred conditions of each cell based on the mean activity in the period in which significant modulation of neuronal activity by conflict level was seen.

\section{Results}

To assess the functional role of sdlPFC, OFC, and PCC in context-dependent executive control adjustment we trained 11 monkeys to perform a version of WCST analog that included trials of two levels of conflict (Mansouri et al., 2007; Figs. 1, 7A); nine monkeys (without any lesion or operation) came from two cohorts of six and three animals that had served as unoperated control animals in two previous studies (Mansouri et al., 2007; Buckley et al., 2009). The six animals of the first cohort, based on preoperative learning scores, were divided into three to receive OFC lesions and three to receive sdlPFC lesions so that the mean and range of the numbers of preoperative rule shifts were comparable between groups. The second cohort of three monkeys was assigned to the PCC lesion group. The circumscribed lesions were made with the help of a high-magnification operating microscope with an intention to minimize inadvertent damage to the surrounding cortical areas or underlying white matter. We compared the preoperative and postoperative performance of the monkeys in each group and therefore the preoperative performance in each group served as the control for the postoperative performance in that particular group. Single-cell activity was recorded from the OFC of two other intact monkeys (see Fig. 7C).

In each trial, the monkeys had to select one of three different test items that matched a sample based on the currently relevant matching rule (color or shape). The relevant rule and its frequent changes (whenever the animals achieved $85 \%$ correct in 20 consecutive trials) were not cued and therefore the subjects faced a conflict/competition between the potential matching rules.

\section{Lesion extent}

In all the lesion groups, the resulting lesions were as intended (Figs. 2-4). Our previous study (Buckley et al., 2009) showed that 
A Pre-operative Post-operative

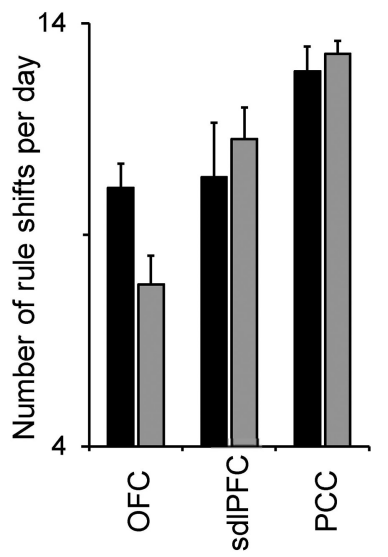

D

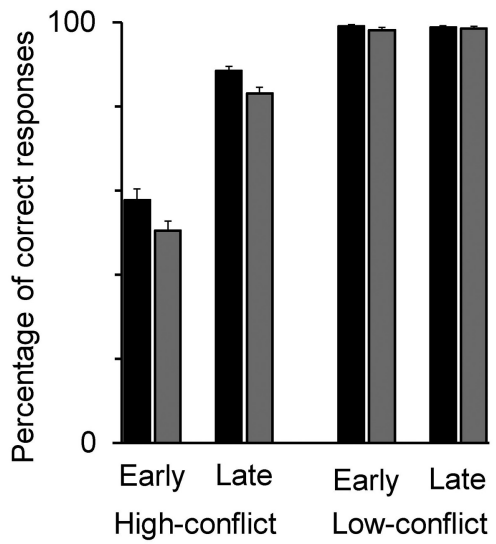

B

High-conflict

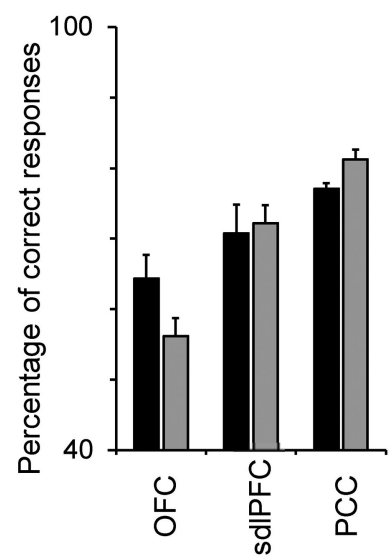

C

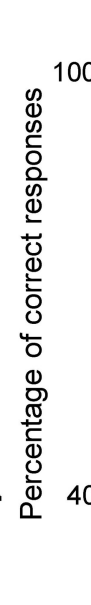

Low-conflict

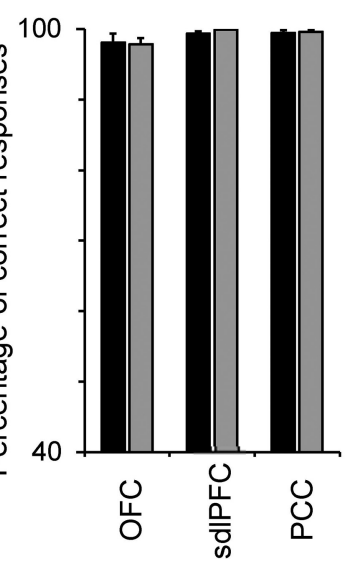

worth et al., 2011). The lesion extent in our study included different regions within OFC including ventromedial and lateral orbital prefrontal cortex (Rushworth et al., 2011) and our recording was limited to an area depicted in Figure $7 C$ and therefore we were unable to dissociate the functions of subregions within OFC. Future studies selectively targeting circumscribed areas within OFC would be necessary to show the crucial function of OFC subregions in the WCST.

\section{Effects of lesions on number of rule shifts and percentage of correct responses}

Data were collected from six consecutive daily sessions preoperatively and also from six consecutive daily sessions postoperatively. We found that the number of rule shifts per daily session decreased after OFC lesions, but not after sdlPFC or PCC lesions. Preoperatively the OFC, sdlPFC, and PCC groups successfully performed the task as evidenced by their abilities to make $10.1 \pm 0.58,10.8 \pm 1.1$, and $12.2 \pm$ 0.2 shifts (mean $\pm \mathrm{SE}$ ) between matching rules per daily session, respectively. Because the number of trials provided within a daily session was fixed to 300 , the number of rule shifts per day is a measure of the overall performance of monkeys in adapting to rule-changes. The numbers of rule-shifts in postoperative testing were $7.83 \pm 0.7,11.3 \pm 0.8$, and $12.4 \pm 0.34$ in OFC, sdlPFC, and PCC groups, respectively. A two-way ANOVA test [monkey (between-subject factor) $\times$ lesion (pre/ post, within-subject factor)] applied to the number of rule-shifts showed that there was no significant change in the number of rule-shifts between the preoperative and postoperative tests in sdlPFC and PCC groups (main effect of lesion, sdlPFC group: $F_{(1,15)}=1.9 ; p=0.19 ;$ PCC

Figure 5. Behavioral consequences of bilateral lesions in OFC, sdIPFC, or PCC. $A$, The mean number of rule-shifts is shown for preoperative and postoperative performances. $B, C$, The mean percentage of correct responses averaged over all the trials in highand low-conflict trials. It was low in high-conflict trials because the monkeys' performance dropped to a very low level in highconflict trials after rule shifts. Percentage of correct responses in high-conflict trials decreased after lesions were made in $\mathrm{OFC}$, but not in sdIPFC or PCC. OFC-lesioned monkeys were not impaired in performing low-conflict trials. $\boldsymbol{D}$, The mean percentage of correct responses of OFC group in low-conflict and high-conflict trials, separately shown for the early (first 10 trials) and late (the last 10 trials) parts of individual blocks. The performance in high-conflict trials was low in the early part but recovered to a high level toward the end of the block. The percentage of correct responses significantly decreased postoperatively in both early and late parts of individual blocks. $\boldsymbol{E}$, The same as $\boldsymbol{D}$, but for LH (high-conflict after low-conflict) and HH (high-conflict after high-conflict) trials.

monkeys with lesions within ventrolateral prefrontal cortex were impaired in even applying matching rules (color- or shapematching) in a control test that required rule-based matching with no rule-shift within a daily session. Therefore, in our current study, we aimed at making complete and bilateral lesions within OFC without affecting the nearby cortical areas (such as ventrolateral prefrontal cortex). We achieved this goal as shown in Figure $2 B$, where the black arrows indicate the lateral and medial limits of the OFC lesions. Correspondingly, although our OFClesioned monkeys were impaired in performing the WCST, they had intact ability in rule-based matching evidenced by their intact performance in the control test with no rule-shift within a day. Also, by inspecting just dorsal and just lateral to the most medial arrows in OFC1, OFC2, and OFC 3 animals (Fig. 2B), it may be appreciated that the white matter was largely spared.

OFC includes different cytoarchitectural regions with different anatomical connections and therefore different regions within OFC might support different cognitive functions (Rush- group: $\left.F_{(1,15)}=0.3 ; p=0.69\right)$. However, a significant decrease in the number of rule-shifts per session was seen after lesions were made in OFC (main effect of lesion: $F_{(1,15)}=12.49 ; p=0.003$; Fig. 5A).

The reduction in the number of rule shifts per daily session after OFC lesions was due to an impairment of performance in high-conflict trials. A three-way ANOVA [monkey (betweensubject factor) $\times$ lesion (pre/post, within-subject factor $) \times$ conflict (high/low, within-subject factor)] applied to the percentage of correct responses showed a significant interaction of lesion and conflict factors $\left(F_{(2,15)}=12.52 ; p=0.003\right)$ in addition to significant main effects of lesion $\left(F_{(1,15)}=15.93 ; p=0.001\right)$ and conflict $\left(F_{(1,15)}=674.53 ; p<10^{-13}\right)$ factors in the OFC group. A follow up two-way ANOVA (monkey $\times$ lesion) applied separately to the percentage of correct responses in low- and highconflict trials showed that the main effect of Lesion was significant in high-conflict $\left(F_{(1,15)}=15.12 ; p=0.001\right)$, but not in low-conflict trials $\left(F_{(1,15)}=0.49 ; p=0.49\right)$. This indicates that 
monkeys' performance after the OFC lesion was significantly impaired in the high-conflict, but not in the low-conflict, trials (Figs. $5 B, C$ ). The percentage of correct responses in high-conflict trials was low in the early part of individual blocks immediately after the rule change and increased in the late part of individual blocks. The OFC lesions consistently reduced the percentage of correct responses in both early (the first 10 trials after rule switch) and late (the last 10 trials before rule switch) parts of individual blocks. A two-way ANOVA test [monkey (between-subject factor) $\times$ lesion (pre/post, within-subject factor)] applied to the percentage of correct responses in early part of the block showed a significant main effect of lesion in OFC group $\left(F_{(1,15)}=5.1 ; p=\right.$ 0.039). The same ANOVA applied to the percentage of correct responses in late part of the block also showed a significant main effect of lesion $\left(F_{(1,15)}=12.26\right.$; $\left.p=0.003\right)$ (Fig. $\left.5 D\right)$. No reduction in percentage of correct responses in low-conflict trials confirms that OFC-lesioned monkeys did not have any problem in perceptual, motor, or matching abilities because the impairment only appeared when the monkeys had to resolve the conflict between the matching rules. Additional control tests also confirmed that OFC-lesioned monkeys did not have any impairment in rule-based (color or shape) matching.

\section{Effects of lesions on behavioral modulation by conflict in the current trial}

We found that, similar to the behavioral effects of conflict in humans, the level of conflict between behavioral rules influenced the monkeys' behavior in current as well as in subsequent trials. With regard to current trials we found that target selection was slowed by the presence of conflict in all the monkey groups (Fig. $6 \mathrm{~A}$ ): the STS (which was calculated as the reciprocal of the time between the test item onset and the first screen touch) was slower in high-conflict trials indicating that the presence of conflict adversely affected the monkeys' performance (conflict cost). To examine the effect of conflict experienced in the current trial on STS, the mean of STS was calculated separately for low- and high-conflict trials in each response direction (left, right, and bottom) in each of the six preoperative testing sessions. A threeway ANOVA [monkey (between-subject factor) $\times$ conflict (low/ high, within-subject factor) $\times$ response direction (within-subject factor)] applied to the mean STS values showed a significant main effect of conflict factor (OFC group: $F_{(1,15)}=41.40 ; p=0.00001$; sdlPFC: $F_{(1,15)}=205.38 ; p<10^{-9}$; PCC group: $F_{(1,15)}=79.32$; $\left.p<10^{-6}\right)$.

To examine the effect of lesions on conflict cost, we calculated one normalized grand average (across sessions and directions) for each monkey and used it for the statistical analyses. A paired $t$ test applied to the differences in conflict cost (low-conflict - highconflict) between the preoperative and postoperative performances showed that there was no significant change in the conflict cost following OFC lesion (one-tailed, $t_{(2)}=0.35, p=$ 0.38 ) or mdlPFC lesion (one-tailed, $t_{(2)}=0.19, p=0.44$ ) or PCC lesion (one-tailed, $t_{(2)}=0.86, p=0.24$ ) indicating that the modulation of STS by the current conflict did not depend on any of OFC, sdlPFC, or PCC (Fig. 6A). Our previous study also showed that lesions in ACC or mdlPFC did not impair the behavioral effects of the currently experienced conflict. These findings indicate that the adverse effects of current conflict level on the STS do not depend on the integrity of ACC, mdlPFC, sdlPFC, PCC, or OFC. Other brain areas, or a very distributed network, might mediate the effect of current conflict level on STS.
A Low conflict
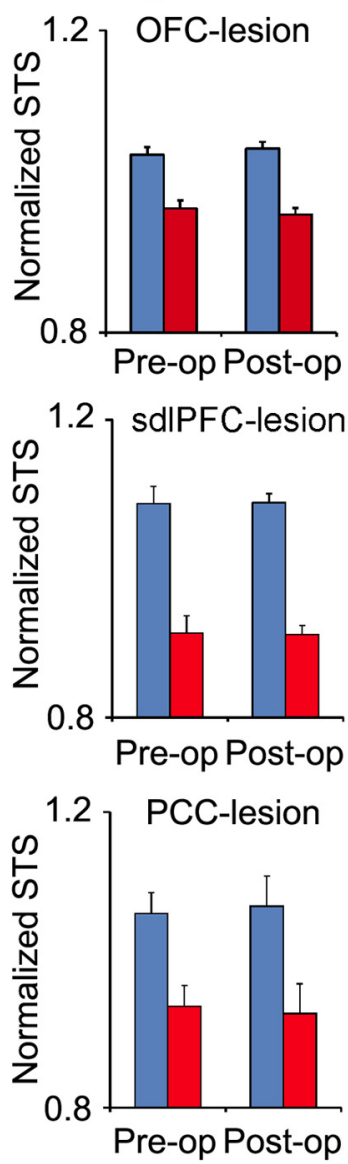

B

$\mathrm{HH}$ $\mathrm{LH}$
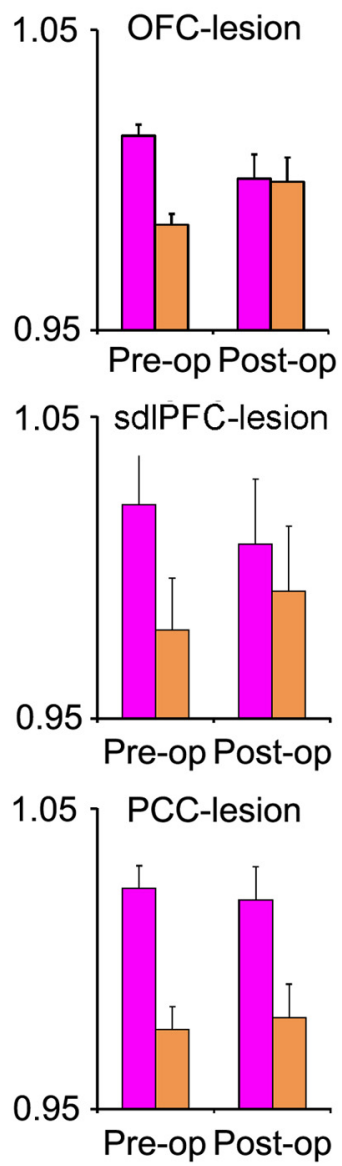

Figure 6. Conflict-induced behavioral adjustments. The panels in top, middle, and bottom rows show the behavioral measures in OFC-, SdIPFC-, and PCC-lesioned groups, respectively. $\boldsymbol{A}$, The mean normalized STS in low-conflict and high-conflict trials. Lesions within OFC or sdIPFC or $P C C$ did not make any significant change in the difference between low-and high-conflict trials. $\boldsymbol{B}$, The preoperative and postoperative STS in LH (high-conflict after low-conflict) and HH (highconflict after high-conflict) trials. The difference in STS between $\mathrm{LH}$ and $\mathrm{HH}$ trials was significantly decreased after lesions were made in OFC.

Effects of lesions on behavioral modulation by conflict in the previous trial

To estimate the behavioral effect of conflict experienced in the previous trial (conflict-adaptation effect), we measured the difference in STS between those high-conflict trials that followed low-conflict trials ( $\mathrm{LH}$ condition) with those high-conflict trials that followed high-conflict trials (HH condition). STS was calculated in the second trial of each $\mathrm{LH}$ or $\mathrm{HH}$ trial sequence. All pairs of consecutively correct trials were used in this calculation. To examine the effect of conflict experienced in the previous trial on STS, the mean of STS was calculated separately for LH and $\mathrm{HH}$ trials in each response direction (left, right, and bottom) in each of the 6 preoperative testing sessions. Preoperatively, the monkeys' STS was faster in $\mathrm{HH}$ than $\mathrm{LH}$ trials in all the monkey groups (Fig. $6 B$, preoperative): a three-way ANOVA ([monkey (between-subject factor) $\times$ previous conflict $(\mathrm{LH} / \mathrm{HH}$, withinsubject factor) $\times$ response direction (within-subject factor) $]$ applied to the mean STS values showed a significant main effect of previous conflict factor (OFC group: $F_{(1,15)}=4.40 ; p=0.054$; sdlPFC: $F_{(1,15)}=9.10 ; p=0.009$; PCC group: $F_{(1,15)}=14.10 ; p=$ $0.002)$. However, lesions in OFC, sdlPFC and PCC had different 

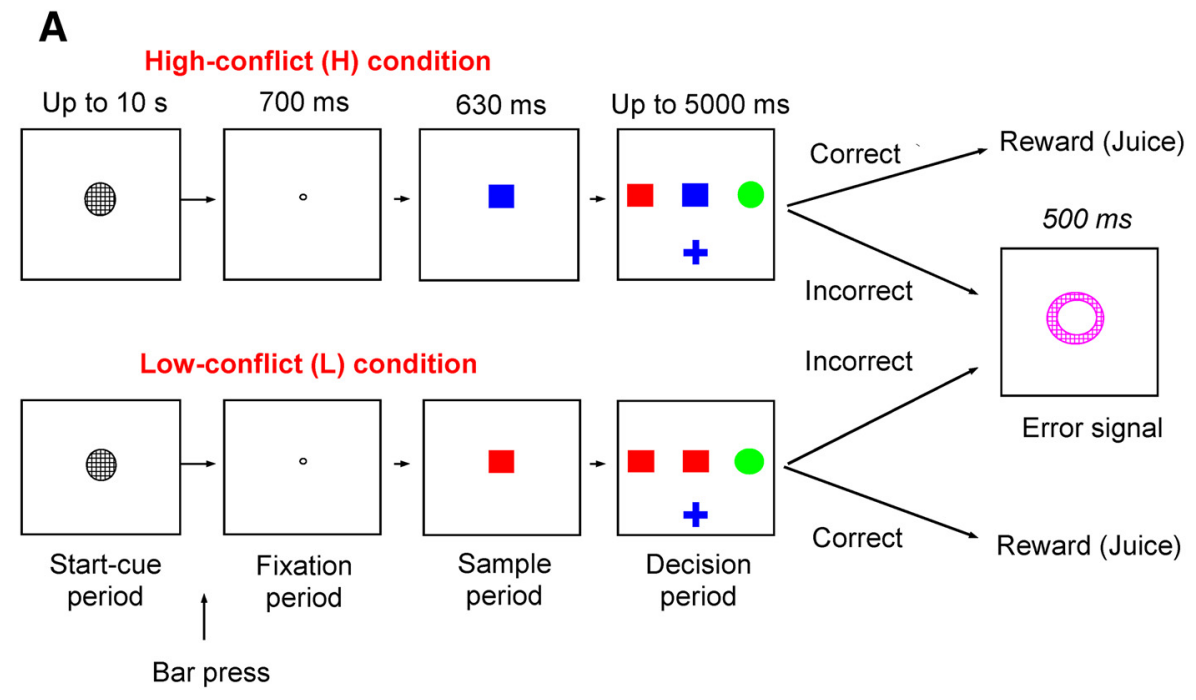

B

C

Recording area

Free-reward trials

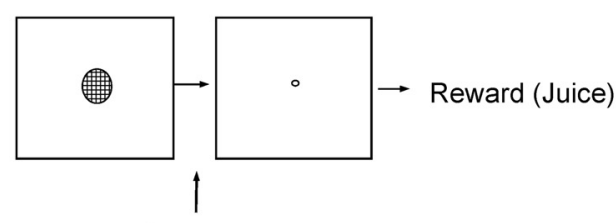

Bar press

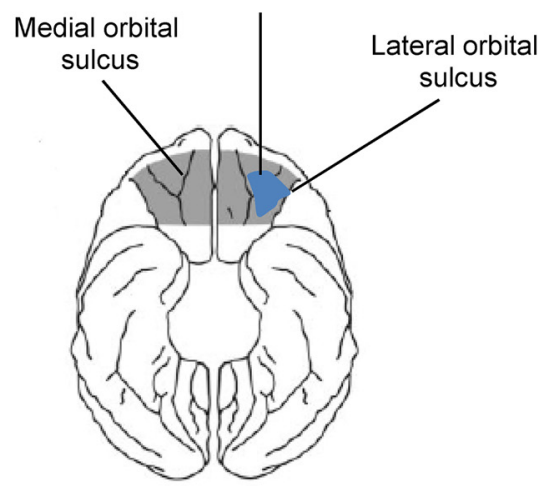

Figure 7. WCST analog used in the cell-recording study. $A$, In each trial, a start cue appeared when an intertrial interval was over. The bar pressing changed the start cue to a fixation point. If the monkey kept pushing the bar and maintained its gaze on the fixation point for $700 \mathrm{~ms}$, a sample stimulus replaced the fixation point. If the monkey maintained eye fixation and bar press for another $630 \mathrm{~ms}$, three test items appeared (to the left, right, and below the sample). The relevant rule for matching (matching by shape or matching by color) was consistent within a block of trials, and it changed without any notice to the monkey when a criterion of $85 \%$ correct performance was achieved. The relevant rule was not cued and the monkeys were only able to identify it by applying a rule and then interpreting the reward or error feedback in the context of the applied rule. B, Free-reward trials. In each trial the bar pressing changed the start cue to a fixation point, if the monkey maintained eye fixation and bar pressing for $630 \mathrm{~ms}$, instead of the sample onset, a reward (the same type and amount as the reward in ordinary trials) was given. $C$, The extent of lesioned area (gray shading) on ventral view of the brain in OFC group. Single-cell recording was conducted in the area depicted in dark blue color.

consequences in each group: a paired $t$ test comparing conflictadaptation $(\mathrm{HH}-\mathrm{LH})$ between the preoperative and postoperative performances showed that there was a significant decrease in conflict-adaptation in OFC group (one-tailed, $t_{(2)}=11.6, p=$ 0.0037 ) but not in sdlPFC (one-tailed, $t_{(2)}=1.32, p=0.16$ ) or PCC (one-tailed, $t_{(2)}=0.44, p=0.35$ ) group (Fig. $6 B$ ).

Preoperatively, the percentage of correct responses in the second trials of $\mathrm{HH}$ trials was significantly higher than that in $\mathrm{LH}$ trials. A $t$ test (two-tailed paired) applied to the mean percentage of correct responses showed that there was a significant difference between $\mathrm{HH}$ and LH trials in OFC group $\left(t_{(2)}=7.6, p=0.017\right)$, in sdlPFC group $\left(t_{(2)}=19.4, p=0.0026\right)$, and in PCC group $\left(t_{(2)}\right.$ $=5.37, p=0.033)$. Postoperatively, whereas the percentage of correct responses in both $\mathrm{HH}$ and $\mathrm{LH}$ trials decreased, the difference between them did not change from the preoperative difference. A $t$ test applied to the differences of percentages of correct responses between $\mathrm{HH}$ and $\mathrm{LH}$ trials in the preoperative and postoperative sessions showed that there was no significant difference between preoperative and postoperative performances following OFC lesion (one-tailed paired $t$ test $t_{(2)}=0.4, p=$
$0.36)$, sdlPFC lesion $\left(t_{(2)}=1.6, p=0.13\right)$, or PCC lesion $\left(t_{(2)}=\right.$ $0.64, p=0.29)$. This was the case for both the early and late parts of individual blocks (OFC group, early part of block: $t_{(2)}=0.15$, $p=0.45$; late part of block: $t_{(2)}=0.34, p=0.38$; Fig. $5 E$ ). Thus, the OFC lesions reduced the effects of the conflict experienced in the previous trial on the speed of target selection, but not the percentage of correct responses. This differential effect of brain lesion on modulation of response time and response accuracy was previously reported in humans with other conflict tasks (Gehring and Knight, 2000): the percentage of correct responses was not different between patients with brain damage and control subjects, whereas a significant difference in response latency could still be detected between the patients and control group. It was suggested that the response-time was a more sensitive behavioral measure. Because our previous study (Buckley et al., 2009) had shown that OFC lesion significantly increased the response time of monkeys, we provided a relatively long response window (5000 ms) for monkeys. This response window allowed us to avoid many time out trials (trials in which the monkey fail to 


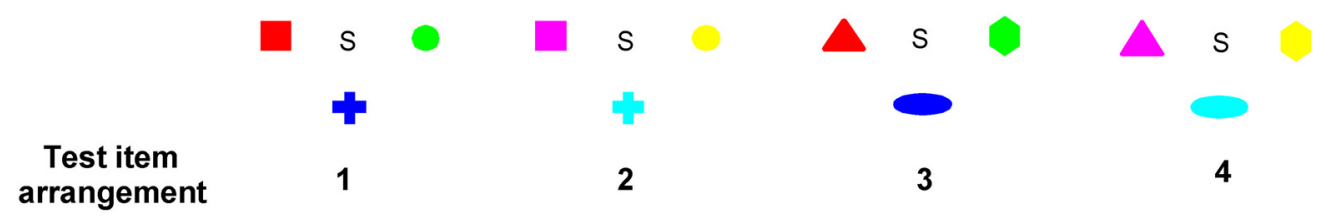

Low conflict

High conflict

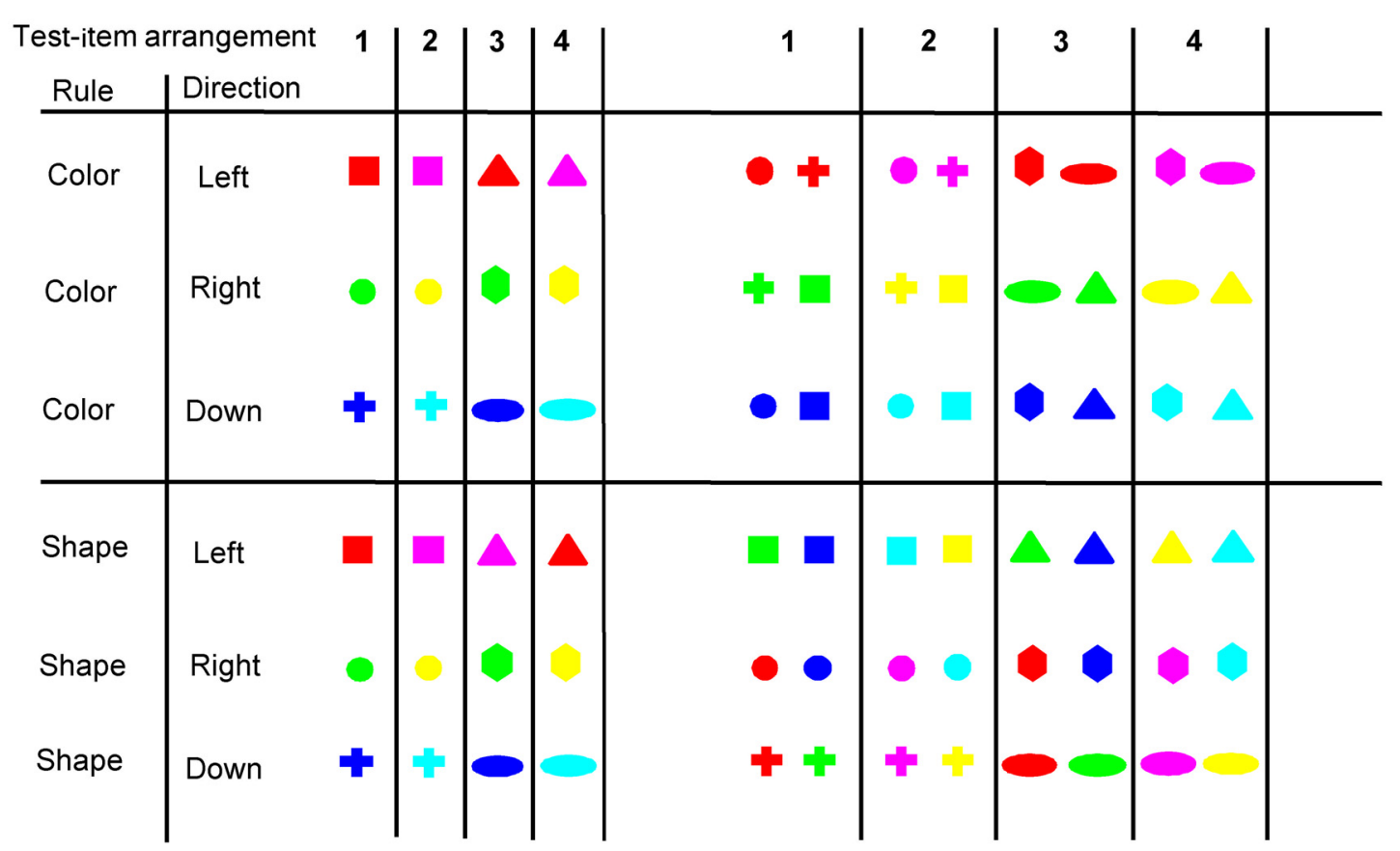

Figure 8. Combinations of samples and test items arrangements presented in the cell-recording study to make the low-conflict and high-conflict conditions. The four test item arrangements are numbered and shown at the top, with " $S$ " in the middle representing the sample. The numbers in the first line of table indicates the test item arrangement used for samples shown below. The two leftmost columns indicate the relevant matching rule and appropriate response-direction. Twelve and 24 samples were shown in the low-conflict and high-conflict conditions, respectively. There were 32 combinations of samples shown in the low-conflict condition and those shown in the high-conflict conditions $(4 \times 8)$ in each response direction with each rule. The number of combinations summed to 192 with three response directions and two rules. We compared the firing rate of cells in these 192 combinations to examine the consistency of selectivity for conflict condition.

respond within the response window) and measure the exact distribution of response time.

\section{Neuronal activity in OFC modulated by the conflict in the current trial}

Our findings indicated that lesions within OFC, but not in sdlPFC or PCC, impaired a behavioral index of trial-by-trial context-dependent adjustment of executive control. We then explored the neural mechanisms underlying the impairment by recording single cell activity in OFC of two intact monkeys (M1 and M2). Both monkeys successfully performed the WCST ana$\log$ (Figs. $7 A, B, 8$ ) even with the additional requirement of eye fixation. Monkeys M1 and M2 had $11.5 \pm 0.27$ and $6.8 \pm 0.25$ (mean $\pm \mathrm{SE}$ ) rule-shifts per daily session. For both monkeys, the STS was significantly slower in high-conflict trials than in lowconflict trials in all three response directions (Fig. 9A), and the STS in HH trials was significantly faster than that of LH trials in all three response directions (Fig. 9B). In contrast to the lesion study, in the recording study, because different samples were consistently used in the high-conflict and low-conflict trials (Figs. $7 A, 8)$, the monkeys could know the conflict level of the trial as soon as the sample was presented. This design allowed us to compare the activity between the two conflict levels while the hand- and eye-positions were fixed and before the monkey had initiated its motor response (Mansouri et al., 2007).

We found that the OFC cell activity differed between lowconflict and high-conflict trials in the sample and decision periods. When we applied a two-way ANOVA (conflict $\times$ rule) to the activity in correct trials of 244 recorded cells, we found that 48 cells $(19.7 \%)$ and 61 cells $(25 \%)$ showed a significant $(p \leq 0.05)$ main effect of conflict in the sample and decision periods, respectively (Fig. 10, an example cell; Fig. 13 A, B, population of cells). These numbers of cells were significantly greater than the number of cells we could obtain by chance (binomial tests, sample period: $p<10^{-10}$; decision period: $\left.p<10^{-10}\right)$. None of these cells showed a significant interaction between the rule and conflict factors indicating that the activity difference between lowand high-conflict trials was independent from the relevant rule. The activity was higher in high-conflict trials in some cells (21/48 and 30/61 cells in the sample and decision periods, respectively) and higher in low-conflict trials in others. Because STS differed between low- and high-conflict trials, an analysis of cell activities with a time window around the response (decision period activity) may have been contaminated by an artifact: activities locked to the test items onset or monkey's response might have produced a pseudo dependency on the trial type by truncating rising 
A

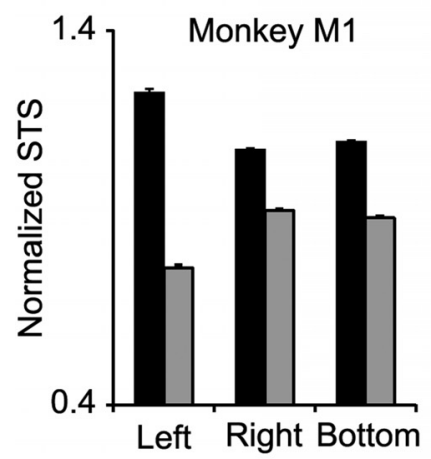

\section{Low conflict}

\section{High conflict}

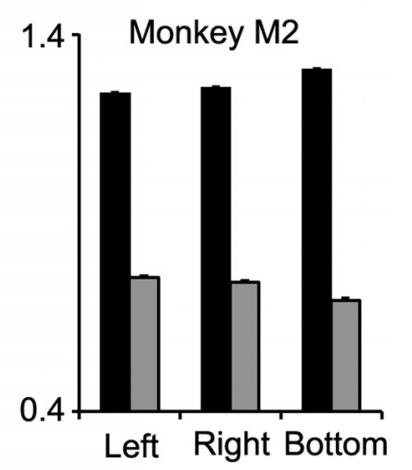

B

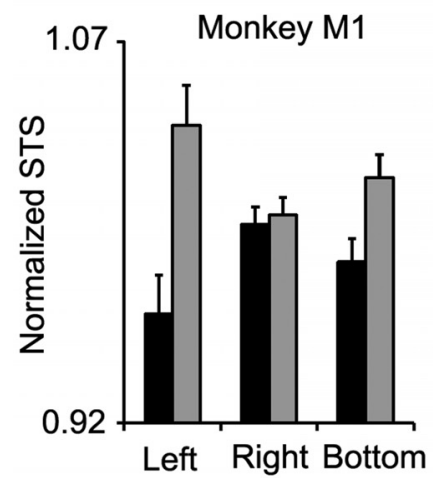

LH

$\mathrm{HH}$

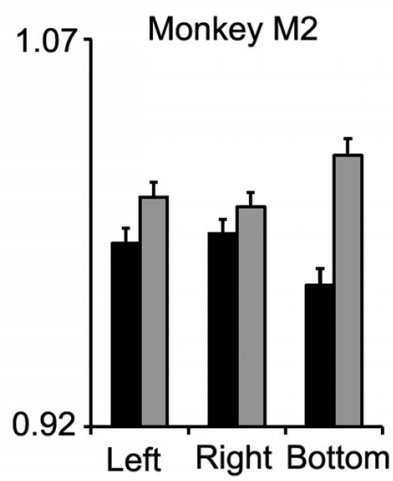

Figure 9. The conflict experienced in current and previous trials influenced monkeys' behavior in the single cell recording study. $\boldsymbol{A}$, The normalized mean STS in low-conflict and highconflict trials is shown for the two monkeys, separately for the three response directions. For both monkeys, in all the three response directions, the STS was significantly faster in lowconflict trials. $\boldsymbol{B}$, The normalized mean STS in the second trial of $\mathrm{HH}$ and $\mathrm{LH}$ trial sequences is shown for each monkey. For both monkeys, the normalized STS in HH trials was higher than that of $L$ H trials.

or falling activities locked to one event by the window locked to the other event. We excluded such effects by subtracting STSdependent components of cell activities from the original (before the mean difference subtraction) values of cell activities and then compared the neuronal activities between low- and high-conflict trials (see Materials and Methods). We also examined whether this activity differences between low- and high-conflict trials resulted from nonspecific factors (see below).

Neuronal responses to reward were influenced by the level of conflict experienced during the course of achieving the reward

We also found that in another group of OFC cells, neuronal responses to reward were influenced by the level of conflict experienced during the course of achieving the reward. It is known that OFC cells represent attributes of expected and obtained reward (Thorpe et al., 1983; Tremblay and Schultz, 2000; Hikosaka and Watanabe, 2000; Lee et al., 2007; Wallis, 2007; PadoaSchioppa and Assad, 2008; Simmons and Richmond, 2008; Schoenbaum et al., 2009; Kobayashi et al., 2010; Hosokawa et al., 2013). A $t$ test comparing the difference in neuronal activity between pre-reward and postreward periods (reward response) showed that 152 of 244 OFC cells $(62.3 \%)$ significantly ( $p \leq$
0.025 ) changed their activity after the reward delivery in low- or high-conflict trials. A two-way ANOVA [conflict (low/high) $\times$ rule (color/shape)] applied to these reward-responses showed that there were significant main effects of conflict or significant interactions ( $p \leq 0.025$ ) for 40 cells $(26.3 \%)$. This number of cells is significantly greater than the number of cells that could be obtained by chance (binomial test, $p<10^{-9}$ ). Three example cells that showed significant effects of conflict are shown in Figures 11 and 12 (Fig. 13C, population activity). Our further analyses of neuronal activity in free-reward trials and in relation to changes in reward expectation from early to later parts of individual trial blocks indicated that the conflict-related activity modulation was not related to different levels of reward expectation (see below).

Activity difference between low- and high-conflict trials was not due to selectivity for physical features of the sample stimuli

Our analyses showed that the activity difference between lowand high-conflict trials was not due to selectivity for physical features of the sample stimuli. As did the example cell shown in Figure 10, most of the 48 and 61 cells showed consistent conflictlevel-dependent activities regardless of the physical identity of the sample stimuli. In the recording study, 12 and 24 samples were presented in low-conflict and high-conflict conditions, respectively. There were 96 combinations of samples presented in lowconflict and high-conflict conditions that required responses in the same direction (4 samples presented in low-conflict conditions $\times 8$ samples presented in high-conflict conditions $\times 3$ directions; Fig. 8). Each combination of samples was presented under the two matching rules and provides two comparisons. Thus, there were 192 comparisons. In 47 of 48 cells (98\%) with significant differences between low- and high-conflict trials in the sample period and in 54 of 61 cells (89\%) with significant differences in the decision period, there were differences in a consistent low- versus high-conflict direction in at least 109 of 192 comparisons (it is $p=0.01$ to obtain this or larger ratios in a cell by chance). We thus statistically confirmed a consistent difference for the majority of cells $(\sim 90 \%)$. The overall probability that these numbers of cells show the consistent differences is extremely low (binomial test: $p<10^{-10}$ ). These results indicate that the currently experienced conflict is encoded in OFC cell activity as a distinct variable independent from physical features of the sample stimuli.

Activity difference between low- and high-conflict trials was not due to effects of differences in certainty about reward on cellular activities

It has been reported that OFC cells modulated their activities depending on the level of reward expectation (Thorpe et al., 1983; Tremblay and Schultz, 2000; Hikosaka and Watanabe, 2000; Lee et al., 2007; Wallis, 2007; Padoa-Schioppa and Assad, 2008; Simmons and Richmond, 2008; Schoenbaum et al., 2009; Kobayashi et al., 2010; Hosokawa et al., 2013). The percentage of correct responses in low-conflict trials was higher than those in highconflict trials, which means that the monkeys received rewards more frequently in low-conflict trials. Then, the monkeys were likely more certain about the upcoming reward in low-conflict trials than high-conflict trials. Therefore, the activity differences between low-conflict and high-conflict trials found in the present study in the sample and decision periods and in the rewardresponse might be caused by the difference in monkeys' certainty 


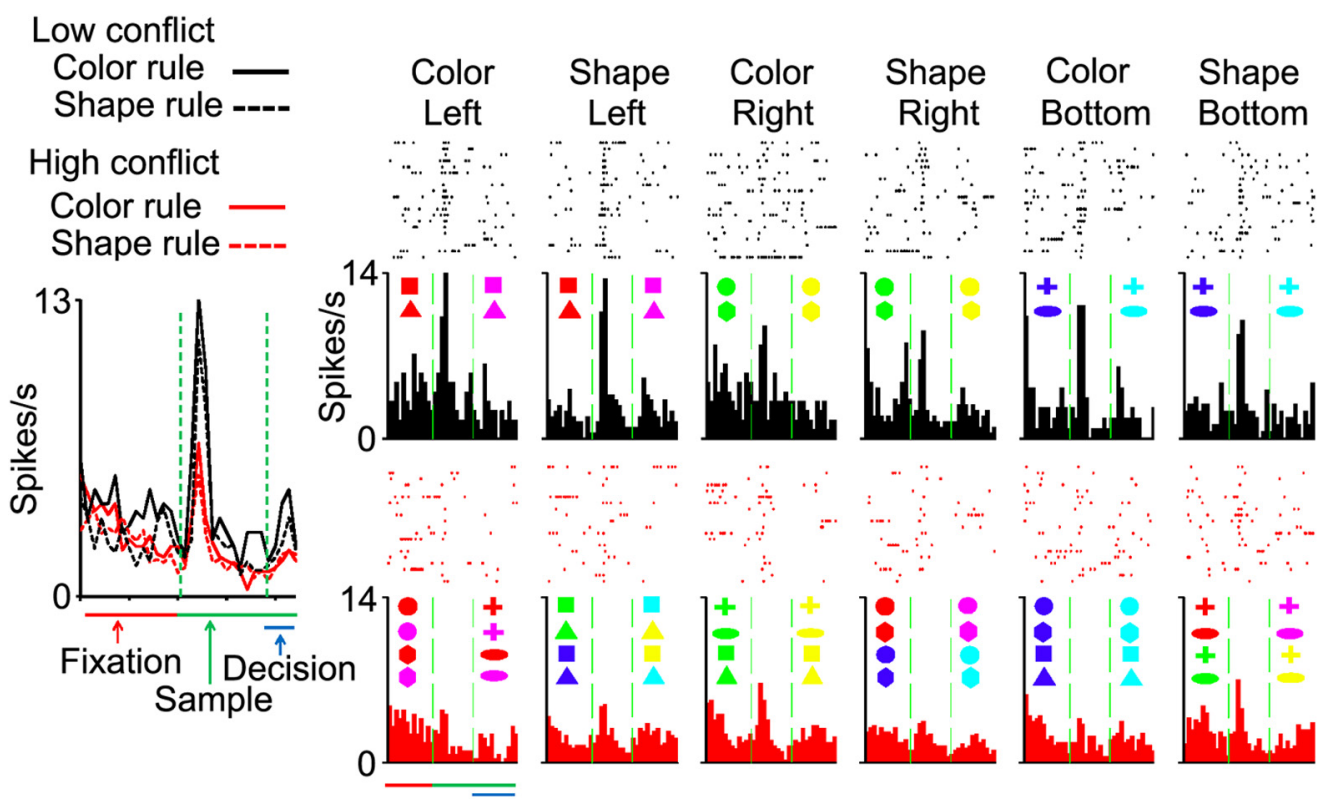

Figure 10. Activities of OFC cells represented currently experienced conflict level; an example cell. The leftmost peristimulus time histograms (PSTH) show activities in low-conflict and high-conflict trials when color- or shape-matching rules were relevant. Each column of the right histograms shows activities in low-conflict (top) and high-conflict (bottom) trials that required the application of the same rule and responses in the same direction. The raster-grams show spikes in individual trials. Samples presented in each condition are shown above individual histograms. Bin-width is $50 \mathrm{~ms}$ for the leftmost PSTH, and $20 \mathrm{~ms}$ for other PSTH. Left and right vertical broken lines indicate the sample and test items onset, respectively. Only correct trials were included.

about reward availability. To evaluate this possibility we made following analyses:

The percentage of correct responses in high-conflict trials was significantly different between the early and late parts of the block (Mansouri and Tanaka, 2002; Mansouri et al., 2006). The percentage was lower after the rule change in the early part of the block. Thus, it is expected that the monkeys were less certain about upcoming reward in the early part of the block. On the other hand, the percentage of correct responses in low-conflict trials was consistently high throughout the block. If the certainty level was the main factor modulating the OFC cell activity, then the difference in certainty level between the early and late parts of the block should have also modulated the neuronal activity, and should have done so only in high-conflict trials.

To examine this possibility, we first applied a two-way ANOVA [early/late $\times$ conflict (low/high)] to activities in lowconflict and high-conflict trials within the first 10 and the last 10 trials of individual blocks. Of 48 cells that showed a significant difference between low-conflict and high-conflict trials in the sample period, only 3 and 4 cells showed significant early/late main effects and significant interactions, respectively. Although the numbers of trials included in this test were smaller than the number used in the ANOVA to examine effects of conflict level, 22 of 48 cells showed significant main effects of Conflict. Therefore, the rareness of a significant interaction cannot be attributed to the paucity of trials and the resulting reduced sensitivity of the test. Of 61 cells that showed a significant difference between lowconflict and high-conflict trials in the decision period, only four and five cells showed significant early/late main effects and significant interactions, respectively, whereas 31 of 61 cells showed significant Conflict main effects. Of 40 cells that showed a significant difference between low-conflict and high-conflict trials in the reward-response, only two and two cells showed significant early/late main effects and significant interactions, respectively, whereas 17 of 40 cells showed significant conflict main effects.

Second, we compared the neuronal activities in high-conflict trials between the early and later parts of the block in cell population. For each cell, we calculated the mean neuronal activity in the sample and decision periods, as well as the mean rewardresponse for the early and late parts of the block. Because the activity was higher in low-conflict trials for some cells and in high-conflict trials for others, the comparisons were conducted separately for each cell group. There were no significant differences in the magnitude of the neuronal activity between the first and last 10 trials in either group of cells (paired $t$ test, for cells with higher activities in high-conflict trials; sample period: $t_{(20)}=$ 1.08, $p=0.29$; decision period: $t_{(29)}=1.08, p=0.29$; rewardresponse: $\left.t_{(19)}=1.73, p=0.101\right)$; for cells with higher activities in low-conflict trials; sample period: $t_{(26)}=0.25, p=0.81$; decision period: $t_{(30)}=0.35, p=0.73$; reward-response $t_{(19)}=0.31, p=$ $0.76)$.

Third, we calculated the correlation between the conflictinduced modulation of neuronal activity (activity in highconflict trials minus activity in low-conflict trials) and the activity difference between high-conflict trials in the early and late parts of the block (activity in the early parts minus activity in the late parts). Because the distribution of difference values significantly deviated from normal distribution (Kolmogorov-Smirnova test, $p<0.05$ ), we used nonparametric correlation test. There was no significant correlation (sample period: Spearman's $\rho=0.13, p=$ 0.38; decision period: Spearman's $\rho=-0.19, p=0.14$ ).

Finally, we examined neuronal responses to free-rewards (Figs. 11, 12). The reward given in free-reward trials was less expected than the rewards given after a response in ordinary high-conflict and low-conflict trials because free-reward trials were randomly presented among ordinary WCST trials. If the uncertainty in reward expectation was the actual factor modulating the neuronal activity, the neuronal response to reward should have been the largest in free-reward trials, intermediate in highconflict trials, and the smallest in low-conflict trials. For all the 40 cells with significant conflict-induced modulation of reward response, we calculated the mean reward responses in low- and 


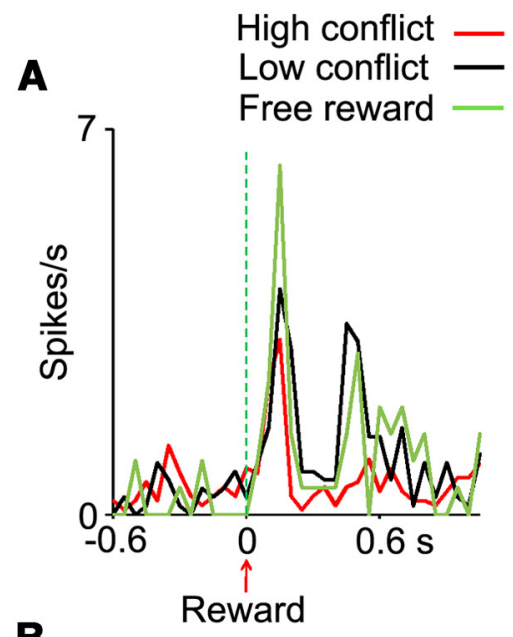

B

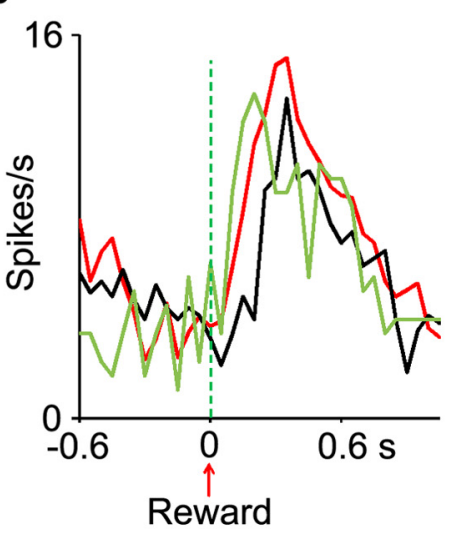

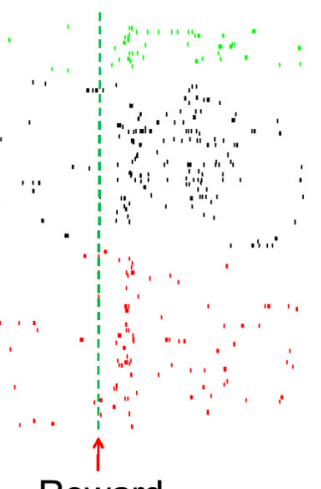

Reward

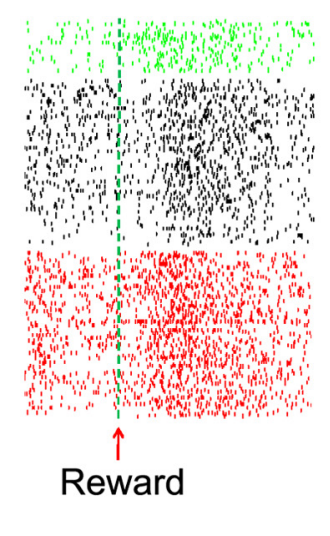

Figure 11. Conflict-dependent activity modulation of two OFC cells. Cellular activity (aligned at reward delivery) was modulated by the conflict experienced in the course of obtaining the reward. $A$, In this cell, the neuronal response to reward had two consecutive components and was the largest in free-reward trials followed by low-conflict and then high-conflict trials. $\boldsymbol{B}$, In this second cell, response to reward was the highest in high-conflict trials. See Figure 12 for an additional example cell.

high-conflict trials, as well as in the free-reward trials separately in color and shape blocks. Of 80 cases ( 40 cells $\times 2$ rules), only in 17 cases there was such an order. The possibility of having the order by chance is $1 / 6$, and the number of cases expected by chance was 13 . Seventeen of 80 is not significantly different from 13 of 80 ( $\chi^{2}$-independence test: $\left.\chi^{2}=0.66, p=0.42\right)$. This means that the difference in the magnitude of reward responses between low- and high-conflict trials cannot be explained by the level of uncertainty in reward expectation.

These results indicated that the modulation of OFC cell activity by the level of conflict experienced in the trial was not related to the different levels of reward expectation or uncertainty between low- and high-conflict trials because the neuronal responses of OFC cells in sample or decision periods were not modulated by the changes in reward expectation from early to later parts of individual trial blocks.

\section{OFC cell activity was not modulated by the conflict}

\section{experienced in the previous trial}

The modulation of behavior in the current trial by the level of conflict experienced in the previous trial requires a mnemonic process to hold the memory of experienced conflict across trials (Mansouri et al., 2007, 2009). We previously (Mansouri et al., 2007) observed that the neuronal activity of mdlPFC in the fixa-
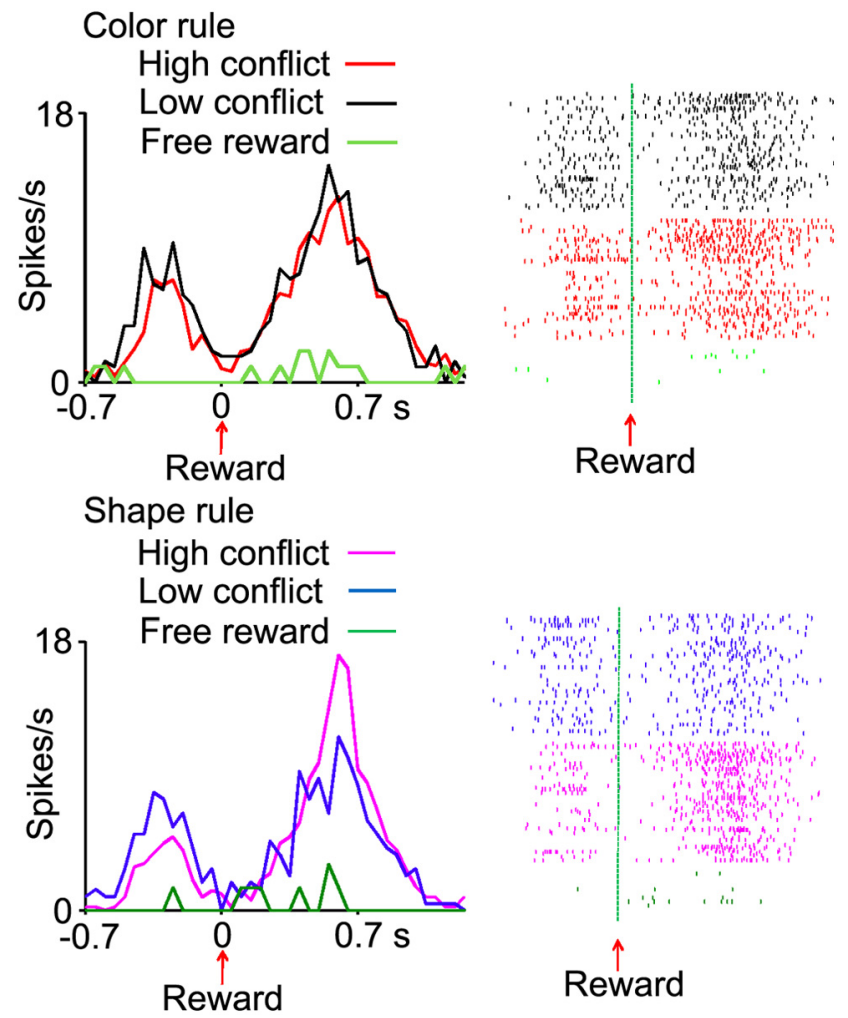

Figure 12. Responses of another OFC cell to rewards were modulated by the experienced conflict. The peristimulus time histograms show activities in low-conflict, high-conflict and free-reward trials, separately for the blocks in which the color- (top) or shape-matching (bottom) rules were relevant. The modulatory effect of conflict on neuronal response to reward was seen when the monkeys applied the shape-matching rule. The neuronal response to reward was much weaker when the same reward was delivered in free-reward trials. The corresponding raster-grams show spikes in individual trials. The neuronal activities are aligned at the time of reward delivery. Bin-size, $50 \mathrm{~ms}$.

tion period was modulated by the level of conflict experienced in the previous trial. Thus, we also compared the cellular activity in OFC between $\mathrm{LH}$ and $\mathrm{HH}$ trials during the fixation period in which the monkeys fixated their hands and eyes but could not know the conflict level in the next trial. We used only the data derived from correct trials that were preceded by correct trials. A two-way ANOVA [previous-conflict $(\mathrm{LH} / \mathrm{HH}) \times$ rule] showed that of the 244 OFC cells, only 11 cells $(4.5 \%)$ had a significant $(p \leq 0.05)$ main effect of previous-conflict. This number of cells is not greater than the number of cells that could be obtained by chance ( $p>0.1$, binomial test). We thus did not observe significant activities in OFC in relation to the maintenance of conflict information across trials.

Thus our results suggest that, although both mdlPFC and OFC are involved in extracting and representing conflict, only mdlPFC is involved in maintaining the conflict information to modulate the upcoming behavior.

\section{Did monkeys implement different strategies in low- and high-conflict trials?}

In the low-conflict condition, the correct response could be found based on the identity of the object, rather than applying the color- or shape-matching rule. Therefore, the monkeys might change the strategy between low-conflict and high-conflict trials: the identity-matching strategy in low-conflict trials and implementing color- or shape-matching rule in high-conflict trials. However, in the WCST analog used in the present study, there 


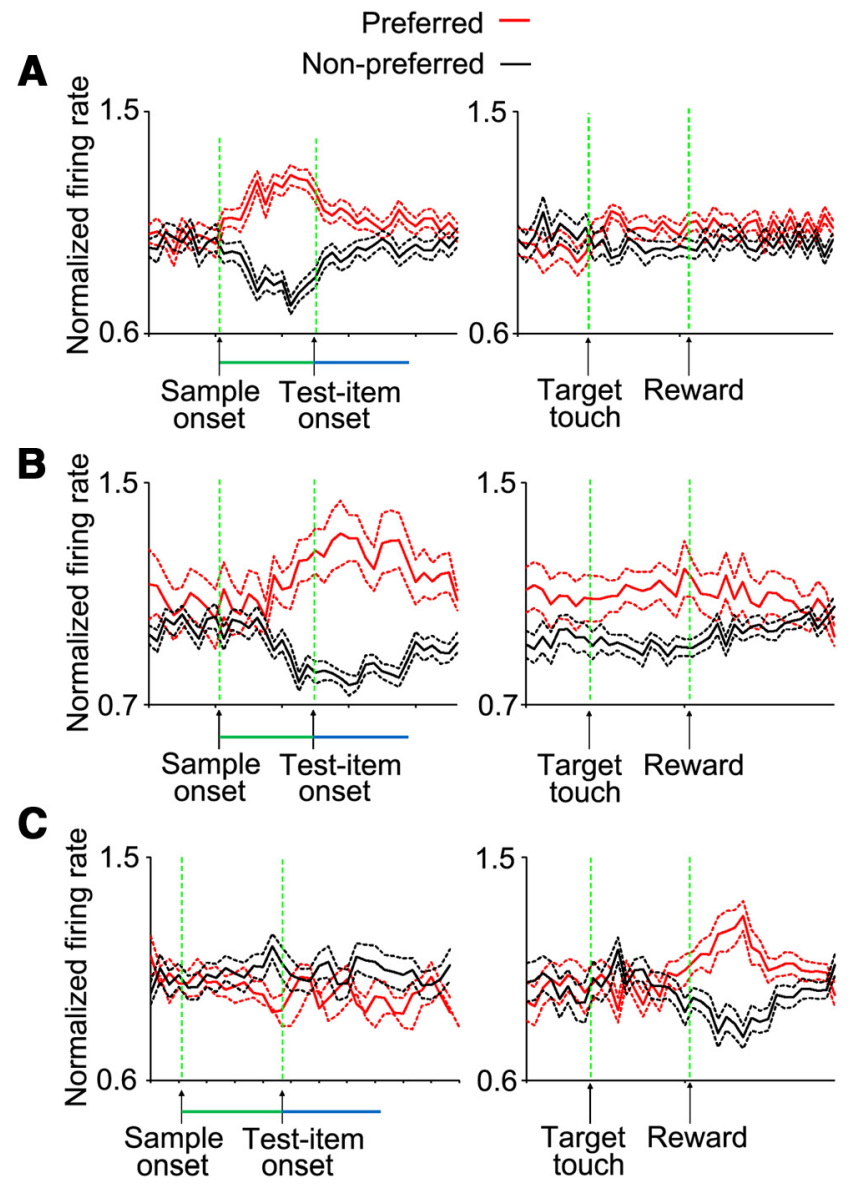

Figure 13. Mean activity of cell populations for the different cell groups that showed significant activity modulation by the conflict level. $\boldsymbol{A}$, The mean activities in 48 cells that showed significant activity modulation by the conflict level during the sample epoch (left). Note that the same population of cells did not show conflict-related activity modulation after the reward delivery (right). $\boldsymbol{B}$, The mean activities in 61 cells that showed significant activity modulation by conflict level during the decision epoch. Note that the same population of cells did not show conflict-related activity modulation after the reward delivery. $C$, The mean activities in 40 cells in which the neuronal response to reward was modulated by the conflict experienced in the course of reward achievement. Note that those cells with significant modulation of their reward response by conflict did not show conflict-level-dependent activity modulation during sample or decision periods. The mean activities in each bin $(55 \mathrm{~ms})$ were calculated for the low- and high-conflict conditions. In each cell, the activities in each bin were normalized by the mean activity in low- and high-conflict conditions in that bin. Because some cells had higher activity in low-conflict conditions and other cells had higher activity in high-conflict condition, the averaged activity across the cells was calculated for the preferred (the conflict condition in which the cell showed the higher activity) and nonpreferred (the conflict condition in which the cell showed the lower activity) conditions. Preferred and nonpreferred conditions are depicted in red and black color, respectively. The dotted lines show the SEM $( \pm)$ in each bin. Left, The activities are aligned at sample onset. Right, The activities are aligned at reward delivery. Green and blue lines in the $x$-axis show the sample and decision periods, respectively.

was no cue for the currently relevant rule, and therefore the monkeys had to maintain the currently relevant rule across trials, in working memory, to respond correctly in high-conflict trials. In addition, low-conflict trials were randomly intermingled with high-conflict trials. Therefore, if the monkeys had used the identity-matching strategy in low-conflict trials, the working memory of the relevant rule should have been maintained, while the monkeys were performing the unrelated task, in low-conflict trials, to be used in the upcoming high-conflict trials. We tested whether macaque monkeys could do this, by putting three types of interruption during the intertrial interval of WCST trials. (1) In a modified versions of the WCST analog (WCST-interruption
Blocks with no interrupion $\square$
Blocks with interruption

A

B

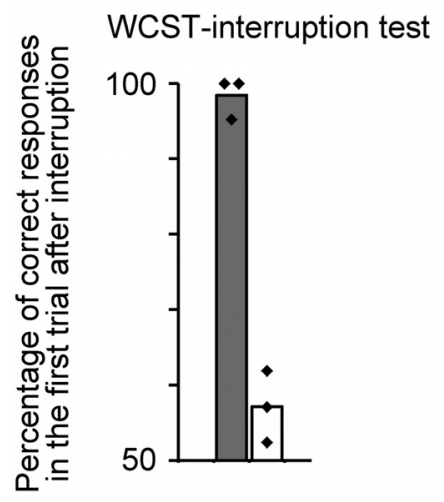

WCST-free-reward test

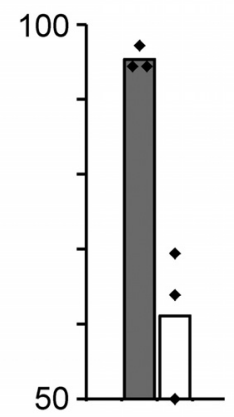

Figure 14. The consequences of interrupting WCST and performance in LH and HH trials. $A$, Interrupting WCST by a face-detection task. Right-side bar shows percentages of correct responses in the first trial of WCST analog following interruption by two consecutive facedetection trials. Left-side bar indicates percentages of correct responses in the same context, but without interruption. $\boldsymbol{B}$, Interrupting WCST by a salient event. Right-side bar shows percentages of correct responses in the first trial of WCST analog following interruption by freereward (two small food pellets). Left-side bar indicates percentages of correct responses in the same context, but without interruption by free-reward. The tilted squares indicate the values of individual monkeys. The free-reward was given in the middle of usual ITI period after the monkeys reached $85 \%$ correct performance (shift criterion). The face-detection task was introduced after the monkey reached the shift criterion. The rule did not change and remained the same in the trial that followed the interruptions.

test), when the monkey' performance reached $85 \%$ by a rule we asked the monkey to perform one or two trials of a face-detection task (touch a face but not a non-face object when they were presented side by side) in a face-detection trial (interruption) and then return to WCST and continue with the same rule which was relevant before the interruption (Buckley et al., 2009). In the first WCST trial after the interruption the monkeys' performance dropped to the chance level (50\%) (Fig. 14A). (2) An increase of the intertrial interval from 6 to $11 \mathrm{~s}$ decreased the performance of control monkeys from 85 to $74 \%$ of correct responses (Buckley et al., 2009, their Fig. 3A). (3) In another version of WCST (WCSTfree-reward test), when the monkey' performance reached $85 \%$ by a rule we gave free-rewards (two food pellets) during the intertrial interval and then required them to continue WCST with the same rule as before the interruption. In the first WCST trial after the free-reward the monkeys' performance dropped to the chance level (Fig. 14B). These results indicated that various types of interruption are very disruptive to the working memory of the currently relevant rule.

Given this fragility of rule working memory, the performance in high-conflict trials following a low-conflict trial (i.e., the second trials of LH trial sequences) should have been close to the chance level if the monkeys had implemented another strategy to perform the low-conflict trials. However, the percentage of correct responses in high-conflict trials following a low-conflict trial was very high in later parts of individual blocks (Figs. 5D,E). These results indicate that even after performing a low-conflict trial (that last for $\sim 18 \mathrm{~s}$, including the intervening intertrial interval) the performance in the following high-conflict condition was $>80 \%$ correct.

The fragility of rule working memory and the high performance in LH trials in the latter parts of individual blocks, together, suggest that the monkeys consistently used the working 
memory of the currently relevant rule in low-conflict as well as high-conflict trials. This is also supported by another piece of evidence obtained with the same WCST task as the one used in the present study: the rule-dependent activities of mdlPFC cells in low-conflict trials were as strong as those in high-conflict trials (Mansouri et al., 2006).

\section{Discussion}

Our behavioral results showed marked similarity in conflictinduced behavioral modulations between monkeys and humans, which enabled us to examine their neural substrate and mechanisms in monkeys. In previous human imaging studies investigating conflict-related processes, although there was OFC activation of in some studies (Bench et al., 1993; Goldstein et al., 2001; Mitchell, 2005), the activation in ACC and mdlPFC has been more frequently observed (Botvinick et al., 2001; Kerns et al., 2004; Carter and van Veen, 2007; Egner, 2007) leading to executive control models that assume crucial roles for ACC and mdlPFC but not for OFC. Here, we found evidence of crucial involvement of OFC, but not sdlPFC or PCC, in these contextdependent executive control adjustments.

Based on imaging and electrophysiogical findings it has been suggested that PCC plays an important role in saliency or change detection (Pearson et al., 2011) and in performance monitoring and exploring the alternative reward sources (Heilbronner and Platt, 2013). However, in our experiments PCC-lesioned monkeys were not impaired in cognitive flexibility (in WCST analog) or the conflict-induced behavioral adjustments. Hence, the aforementioned suggested roles for PCC might be limited to the early learning period or when the task rules and contingencies are unclear, or when frequent changes in reward contingencies require exploring the value of alternative options in a highly dynamic environment.

Previous studies have suggested functional differences between sdlPFC and the cortex surrounding principal sulcus in working memory processes (Petrides, 2005; Buckley et al., 2009). As we previously found that the conflict-induced behavioral adjustment was impaired in mdlPFC-lesioned monkeys (Mansouri et al., 2007), our current finding that the conflict-induced behavioral modulation was intact in sdlPFC-lesioned monkeys indicated another functional distinction between these two closely located and connected prefrontal areas.

It has been generally assumed that the OFC's contribution to cognition is the assignment of value to stimuli, choices, or behavior-guiding rules; a view which is also supported by observations that single cell activity in OFC encodes both primary rewards and the stimuli associated with reward, and that responses to reward-associated stimuli are modulated when reward contingencies change (Thorpe et al., 1983; Dias et al., 1996, 1997; Bechara et al., 2000; Elliott et al., 2000; Hikosaka and Watanabe, 2000; Tremblay and Schultz, 2000; Wallis and Miller, 2003; Roberts, 2006; Wallis, 2007; Rolls, 2004; Fellows, 2007; Lee et al., 2007; Szatkowska et al., 2007; Padoa-Schioppa and Assad, 2008; Simmons and Richmond, 2008; Schoenbaum et al., 2009; Kobayashi et al., 2010; Noonan et al., 2010, 2012; Peters and Büchel, 2010; Walton et al., 2010; Rushworth et al., 2011; Hosokawa et al., 2013). In our previous study (Buckley et al., 2009) we found that after dropping to a chance level following an error commission, there was a rapid learning after a single experience of correct rule-matching and obtaining a reward. This rapid reward-based learning was impaired in OFC-lesioned monkeys and therefore, we proposed that OFC was necessary for assessing the behavioral outcome (reward) to update the value of behavioral rules in the WCST.

OFC-damaged humans and monkeys show impairment in a diverse range of tasks in which decisions should be made among alternative choices (Butter et al., 1963; Butter, 1969; Bachevalier and Mishkin, 1986; Bechara et al., 2000; Izquierdo et al., 2004; Wallis, 2007; Buckley et al., 2009; Camille et al., 2011; Gläscher J et al., 2012). Conflict in information processing is an inherent aspect of many of these tasks, in which context-dependent adjustment of executive control might enhance assessment and learning from behavioral outcome. OFC-damaged subjects are also impaired in tests of executive functions such as the WCST and Stroop test (Bench et al., 1993; Wallis, 2007; Buckley et al., 2009) and imaging studies have shown activation of OFC in tests of executive function (Bench et al., 1993; Goldstein et al., 2001; Mitchell, 2005). The conflict-induced modulation of upcoming behavior has been considered as a behavioral index of conflictinduced executive control adjustment and we found that this was significantly attenuated after OFC lesion. We cannot simply explain this finding based on deficits in reward processing.

Recording the neuronal activity in OFC brings insight to possible mechanisms through which OFC contributes to executive control processes. We found that neuronal activity in OFC represented conflict level as an independent variable (Figs. 10, $13 A, B)$ and maintained this information through to the time of behavioral goal achievement (Figs. 11, 12, 13C). This implies that OFC is involved in conflict representation, which may be a crucial step in the ensuing recruitment of cognitive control and consequently in resolution of conflict. The WCST analog is a multifaceted test that requires participation and coordination of multiple cognitive processes, such as rule-based behavior, inhibition of the irrelevant rule, working memory of rule, and assessment of the behavioral outcome. Therefore, OFC might support conflictinduced executive control recruitment, which could consequently enhance the other cognitive processes that support performance in WCST.

Conflict-induced augmentation of control might enhance selective processing of the relevant rule and its maintenance in working memory and inhibit the irrelevant rule and therefore improve the performance in the upcoming trial. We found that responses of OFC cells to rewards also represented the level of conflict that the monkey had experienced through the course to obtain the reward. This integration of information about conflict and reward in OFC cell activities might support two important aspects of OFC function. First, stabilizing the behavior-guiding rule after reward and promoting change in the implemented rule after no reward are crucial when the reward or no reward results from selection between competing behavioral rules or when there is insufficient information available to determine the appropriate course of action and therefore a proper decision depends on the estimated value of stimuli, responses, or rules obtained through their reward contingencies (Mitchell, 2005). The detection of conflict experienced in the course of reward achievement can adjust the amount of rule value change after the feedback; no change in low-conflict trials but change in high-conflict trials. A related explanation, consistent with the cognitive map of task space model (Wilson et al., 2014), is that OFC lesioned animals failed to disambiguate task state and accordingly failed to implement appropriate task-state-specific strategies, which would be to focus onto the outcome and the rule just applied in the current trial to detect the most advantageous rule (Mansouri et al., 2006; Buckley et al., 2009). 
Second, because conflict resolution can be considered to be cognitively challenging, bringing it to bear upon task performance could be considered an additional cost of performing a task. OFC might represent the conflict-induced cognitive challenge and modulate the evaluation of behavioral outcomes accordingly, that is, depending on the level of cognitive challenges encountered during the course of decision-making, appropriate cost-benefit analyses may be facilitated, which is an important aspect of action evaluation (Lee et al., 2007; Padoa-Schioppa and Assad, 2008; Rangel et al., 2008; Hosokawa et al., 2013).

It has been proposed that in the context of choice behavior OFC might be involved in evaluating the available evidence and constructing an estimate of certainty or confidence about decisions (Kepecs et al., 2008; Mainen and Kepecs, 2009). The confidence or certainty about the upcoming decision might be influenced by the level of conflict in information processing and our results indicate that OFC might be involved in encoding and maintaining conflict information and therefore in informing those processes that construct decision confidence or certainty. However, our findings indicate that the OFC cell activity representing conflict did not necessarily encode uncertainty about the upcoming decision or outcome (reward) because (1) the changes in uncertainty within a block (imposed by periodic yet unannounced rule-changes) did not influence OFC cell activity before or during decision making and (2) the neuronal response to reward was not affected by different levels of reward expectation. Therefore, conflict as an inherent aspect of many tasks involving choice behavior, is represented by mdlPFC and OFC not only for informing certainty or confidence about decision in some tasks but also for adaptive recruitment of executive control to support conflict resolution and to decrease the error likelihood.

\section{Conclusion}

The neuroanatomical connections of OFC place it as an important hub where information regarding the motivational (or emotional) and cognitive (or executive) aspects of a goal-directed behavior can be integrated (Lee et al., 2007; Watanabe and Sakagami, 2007). The OFC might support several core functions depending on the task demands. Representing behavioral outcome (positive and negative) and the value of behavioral options enables several cognitive functions such as informing emotional and motivational aspects of cognition and also assessing and learning from the behavioral outcome for guiding the choice behavior. Encoding the conflict in information processing might enable other cognitive functions such as constructing an estimate of the cost and benefit of a behavioral rule or action; informing internal representation of task state or decision confidence, as well as recruitment of executive control when conflict or uncertainly level (and therefore the error likelihood) is high. Our findings suggest that the role of primate OFC in cognition extends beyond reward-related processing to encode conflict information and the ensuing executive control adjustment.

\section{References}

Bachevalier J, Mishkin M (1986) Visual recognition impairment follows ventromedial but not dorsolateral prefrontal lesions in monkeys. Behav Brain Res 20:249-261. CrossRef Medline

Baleydier C, Mauguiere F (1980) The duality of the cingulate gyrus in monkey: neuroanatomical study and functional hypothesis. Brain 103:525554. CrossRef Medline

Bechara A, Damasio H, Damasio AR (2000) Emotion, decision making and the orbitofrontal cortex. Cereb Cortex 10:295-307. CrossRef Medline

Bench CJ, Frith CD, Grasby PM, Friston KJ, Paulesu E, Frackowiak RS, Dolan RJ (1993) Investigations of the functional anatomy of attention using the stroop test. Neuropsychologia 31:907-922. CrossRef Medline
Botvinick MM, Braver TS, Barch DM, Carter CS, Cohen JD (2001) Conflict monitoring and cognitive control. Psychol Rev 108:624-652. CrossRef Medline

Buckley MJ, Mansouri FA, Hoda H, Mahboubi M, Browning PG, Kwok SC, Phillips A, Tanaka K (2009) Dissociable components of rule-guided behavior depend on distinct medial and prefrontal regions. Science 325:5258. CrossRef Medline

Butter CM (1969) Perseveration in extinction and in discrimination reversal tasks following selective frontal ablations in Macaca mulatta. Physiol Behav 4:163-171. CrossRef

Butter CM, Mishkin M, Rosvold HE (1963) Conditioning and extinction of a food-rewarded response after selective ablations of frontal cortex in rhesus monkeys. Exp Neurol 7:65-75. CrossRef Medline

Camille N, Tsuchida A, Fellows LK (2011) Double dissociation of stimulusvalue and action-value learning in humans with orbitofrontal or anterior cingulate cortex damage. J Neurosci 31:15048-15052. CrossRef Medline

Carter CS, van Veen V (2007) Anterior cingulate cortex and conflict detection: an update of theory and data. Cogn Affect Behav Neurosci 7:367379. CrossRef Medline

Cavada C, Compañy T, Tejedor J, Cruz-Rizzolo RJ, Reinoso-Suárez F (2000) The anatomical connections of the macaque monkey orbitofrontal cortex: a review. Cereb Cortex 10:220-242. CrossRef Medline

Dias R, Robbins TW, Roberts AC (1996) Dissociation in prefrontal cortex of affective and attentional shifts. Nature 380:69-72. CrossRef Medline

Dias R, Robbins TW, Roberts AC (1997) Dissociable forms of inhibitory control within prefrontal cortex with an analog of the Wisconsin card sort test: restriction to novel situations and independence from "on-line" processing. J Neurosci 17:9285-9297. Medline

Egner T (2007) Congruency sequence effects and cognitive control. Cogn Affect Behav Neurosci 7, 380-390.

Elliott R, Dolan RJ, Frith CD (2000) Dissociable functions in the medial and lateral orbitofrontal cortex: evidence from human neuroimaging studies. Cereb Cortex 10:308-317. CrossRef Medline

Fellows LK (2007) The role of orbitofrontal cortex in decision making: a component process account. Ann N Y Acad Sci 1121:421-430. CrossRef Medline

Gehring WJ, Knight RT (2000) Prefrontal-cingulate interactions in action monitoring. Nat Neurosci 3:516-520. CrossRef Medline

Gläscher J, Adolphs R, Damasio H, Bechara A, Rudrauf D, Calamia M, Paul LK, Tranel D (2012) Lesion mapping of cognitive control and valuebased decision making in the prefrontal cortex. Proc Natl Acad Sci U S A 109:14681-14686. CrossRef Medline

Goldstein RZ, Volkow ND, Wang GJ, Fowler JS, Rajaram S (2001) Addiction changes orbitofrontal gyrus function: involvement in response inhibition. Neuroreport 12:2595-2599. CrossRef Medline

Heilbronner SR, Platt ML (2013) Causal evidence of performance monitoring by neurons in posterior cingulate cortex during learning. Neuron 80:1384-1391. CrossRef Medline

Hikosaka K, Watanabe M (2000) Delay activity of orbital and lateral prefrontal neurons of the monkey varying with different rewards. Cereb Cortex 10:263-271. CrossRef Medline

Hosokawa T, Kennerley SW, Sloan J, Wallis JD (2013) Single-neuron mechanisms underlying cost-benefit analysis in frontal cortex. J Neurosci 33: 17385-17397. CrossRef Medline

Izquierdo A, Suda RK, Murray EA (2004) Bilateral orbital prefrontal cortex lesions in rhesus monkeys disrupt choices guided by both reward value and reward contingency. J Neurosci 24:7540-7548. CrossRef Medline

Kepecs A, Uchida N, Zariwala HA, Mainen ZF (2008) Neural correlates, computation and behavioural impact of decision confidence. Nature 455: 227-231. CrossRef Medline

Kobayashi S, Pinto de Carvalho O, Schultz W (2010) Adaptation of reward sensitivity in orbitofrontal neurons. J Neurosci 30:534-544. CrossRef Medline

Lee D, Rushworth MF, Walton ME, Watanabe M, Sakagami M (2007) Functional specialization of the primate frontal cortex during decision making. J Neurosci 27:8170-8173. CrossRef Medline

Mainen ZF, Kepecs A (2009) Neural representation of behavioral outcomes in the orbitofrontal cortex. Curr Opin Neurobiol 19:84-91. CrossRef Medline

Mansouri FA, Tanaka K (2002) Behavioral evidence for working memory of sensory dimension in macaque monkeys. Behav Brain Res 136:415426. CrossRef Medline 
Mansouri FA, Matsumoto K, Tanaka K (2006) Prefrontal cell activities related to monkeys' success and failure in adapting to rule changes in a Wisconsin card sorting test (WCST) analog. J Neurosci 26:2745-2756. CrossRef Medline

Mansouri FA, Buckley MJ, Tanaka K (2007) Mnemonic function of the dorsolateral prefrontal cortex in conflict-induced behavioral adjustment. Science 318:987-990. CrossRef Medline

Mansouri FA, Tanaka K, Buckley MJ (2009) Conflict-induced behavioral adjustment: a clue to the executive functions of the prefrontal cortex. Nat Rev Neurosci 10:141-152. CrossRef Medline

Mayr U, Awh E, Laurey P (2003) Conflict adaptation effects in the absence of executive control. Nat Neurosci 6:450-452. CrossRef Medline

McCoy AN, Plat ML (2005) Risk-sensitive neurons in macaque posterior cingulate cortex. Nat Neuroscience 8:1220-1227. CrossRef Medline

Mitchell RL (2005) The BOLD response during Stroop task-like inhibition paradigms: effects of task difficulty and task-relevant modality. Brain Cogn 59:23-37. CrossRef Medline

Noonan MP, Walton ME, Behrens TE, Sallet J, Buckley MJ, Rushworth MF (2010) Separate value comparison and learning mechanisms in macaque medial and lateral orbitofrontal cortex. Proc Natl Acad Sci U S A 107: 20547-20552. CrossRef Medline

Noonan MP, Kolling N, Walton ME, Rushworth MF (2012) Re-evaluating the role of the orbitofrontal cortex in reward and reinforcement. Eur J Neurosci 35:997-1010. CrossRef Medline

Padoa-Schioppa C, Assad JA (2008) The representation of economic value in the orbitofrontal cortex is invariant for changes of menu. Nat Neurosci 11:95-102. CrossRef Medline

Pearson JM, Heilbronner SR, Barack DL, Hayden BY, Platt ML (2011) Posterior cingulate cortex: adapting behavior to a changing world. Trends Cogn Sci 15:143-151. CrossRef Medline

Peters J, Büchel C (2010) Neural representations of subjective reward value. Behav Brain Res 213:135-141. CrossRef Medline

Petrides M (2005) Lateral prefrontal cortex: architectonic and functional organization. Phil Trans R Soc B 360:781-795. Medline

Rangel A, Camerer C, Montague PR (2008) A framework for studying the neurobiology of value-based decision making. Nat Rev Neurosci 9:545556. CrossRef Medline

Roberts AC (2006) Primate orbitofrontal cortex and adaptive behavior. Trends Cogn Sci 10:83-90. CrossRef Medline
Rolls ET (2004) The functions of the orbitofrontal cortex. Brain Cogn 55: 11-29. CrossRef Medline

Rudebeck PH, Saunders RC, Prescott AT, Chau LS, Murray EA (2013) Prefrontal mechanisms of behavioral flexibility, emotion regulation and value updating. Nat Neurosci 16:1140-1145. CrossRef Medline

Rushworth MF, Noonan MP, Boorman ED, Walton ME, Behrens TE (2011) Frontal cortex and reward-guided learning and decision-making. Neuron 70:1054-1069. CrossRef Medline

Schoenbaum G, Roesch MR, Stalnaker TA, Takahashi YK (2009) A new perspective on the role of the orbitofrontal cortex in adaptive behaviour. Nat Rev Neurosci 10:885-892. CrossRef Medline

Simmons JM, Richmond BJ (2008) Dynamic changes in representations of preceding and upcoming reward in monkey orbitofrontal cortex. Cereb Cortex 18:93-103. CrossRef Medline

Szatkowska I, Szymańska O, Bojarski P, Grabowska A (2007) Cognitive inhibition in patients with medial orbitofrontal damage. Exp Brain Res 181:109-115. CrossRef Medline

Thorpe SJ, Rolls ET, Maddison S (1983) The orbitofrontal cortex: neuronal activity in the behaving monkey. Exp Brain Res 49:93-115. Medline

Tremblay L, Schultz W (2000) Reward-related neuronal activity during gonogo task performance in primate orbitofrontal cortex. J Neurophysiol 83:1864-1876. Medline

Vogt BA, Finch DM, Olson CR (1992) Functional heterogeneity in cingulate cortex: the anterior executive and posterior evaluative regions. Cereb Cortex 2:435-443. CrossRef Medline

Wallis JD (2007) Orbitofrontal cortex and its contribution to decisionmaking. Annu Rev Neurosci 30:31-56. CrossRef Medline

Wallis JD, Miller EK (2003) Neuronal activity in primate dorsolateral and orbital prefrontal cortex during performance of a reward preference task. Eur J Neurosci 18:2069-2081. CrossRef Medline

Walton ME, Behrens TE, Buckley MJ, Rudebeck PH, Rushworth MF (2010) Separable learning systems in the macaque brain and the role of orbitofrontal cortex in contingent learning. Neuron 65:927-939. CrossRef Medline

Watanabe M, Sakagami M (2007) Integration of cognitive and motivational context information in the primate prefrontal cortex. Cereb Cortex 17: i101-109. CrossRef Medline

Wilson RC, Takahashi YK, Schoenbaum G, Niv Y (2014) Orbitofrontal cortex as a cognitive map of task space. Neuron 81:267-279. CrossRef Medline 